IZA DP No. 9721

Public Expenditure, Demography and Growth: Theory and Evidence from India

Pranab Kumar Das

Saibal Kar

February 2016

Forschungsinstitut zur Zukunft der Arbeit Institute for the Study of Labor 


\title{
Public Expenditure, Demography and Growth: Theory and Evidence from India
}

\author{
Pranab Kumar Das \\ Center for Studies in Social Sciences, Calcutta \\ Saibal Kar \\ Center for Studies in Social Sciences, Calcutta \\ and IZA
}

\section{Discussion Paper No. 9721 \\ February 2016}

\author{
IZA \\ P.O. Box 7240 \\ 53072 Bonn \\ Germany \\ Phone: +49-228-3894-0 \\ Fax: +49-228-3894-180 \\ E-mail: iza@iza.org
}

Any opinions expressed here are those of the author(s) and not those of IZA. Research published in this series may include views on policy, but the institute itself takes no institutional policy positions. The IZA research network is committed to the IZA Guiding Principles of Research Integrity.

The Institute for the Study of Labor (IZA) in Bonn is a local and virtual international research center and a place of communication between science, politics and business. IZA is an independent nonprofit organization supported by Deutsche Post Foundation. The center is associated with the University of Bonn and offers a stimulating research environment through its international network, workshops and conferences, data service, project support, research visits and doctoral program. IZA engages in (i) original and internationally competitive research in all fields of labor economics, (ii) development of policy concepts, and (iii) dissemination of research results and concepts to the interested public.

IZA Discussion Papers often represent preliminary work and are circulated to encourage discussion. Citation of such a paper should account for its provisional character. A revised version may be available directly from the author. 


\section{ABSTRACT \\ Public Expenditure, Demography and Growth: Theory and Evidence from India*}

Many countries in the developed world are ageing in terms of their distribution of population. Conversely, a number of countries in the south have younger population. India for example, has $60 \%$ of its population in the age group of 15-59, with the mean age close to 27 years as of present times. The lower share of population in the higher and lower age brackets make the dependency ratio lower than that of the ageing countries. The economic growth such a large share of working age population can usher in lies at the core of the demographic dividends. However, low human capital, poor health and inadequate physical infrastructure seems to create significant hurdles in the potential growth path such countries can achieve. We investigate through an endogenous growth model applied to the Indian macroeconomic data, as to whether public expenditures in education, health and physical infrastructure are conducive to rapid economic growth commensurate with the projected demographic dividends for India. We deploy a Structural Vector Autoregressive Model on data for shares of public expenditure on education and health as the main pillars of growth of human capital in the country, on the per capita GDP growth rate, the working age population, etc. Importantly, we find that a rise in expenditure on health imparts a positive impact on the working age population through greater participation. However, higher allocations for education and training draws workers away from the labor market in a country with large share of unskilled workers and employment opportunities in the large informal sector.

JEL Classification: E24, E6, J2, N3

Keywords: human capital, health, endogenous growth, demographic dividend, public expenditure

Corresponding author:

Saibal Kar

Centre for Studies in Social Sciences, Calcutta

R-1, B. P. Township

Kolkata 700094

India

E-mail: saibal@cssscal.org

\footnotetext{
* The authors thank CTRPFP for financial support towards this research. Research assistance from Srijan Banerjee and Iman Pal are duly acknowledged. The usual disclaimer applies.
} 


\section{Introduction}

It is globally accepted that countries like China, India, Brazil, South Africa and the Russian Federation demonstrated commendable economic growth over the last two decades amidst sweeping changes in their economies. Albeit, the economic and financial reforms, which are credited for such changes occurred at different times for these countries the outcomes seem quite similar by the time these economies settled onto their respective growth trajectories. It is no wonder then that the global economic forums recognize these economic successes as defining the new economic order, despite admission of critical internal disadvantages that continue to group these countries alongside other developing and transition economies. The present chapter attempts to review the macroeconomic and financial conditions prevailing in India during this important transition period. The main focus of this study is to explore and observe the possible connections between the changing demographic pattern in the country and the economic growth it has endured over a substantial period. The Indian experience should indicate and be largely amenable to important policies for general economic development in similar countries.

Furthermore, it has been lately acknowledged that the relationships between important conduits of economic growth and the growth itself may be quite different across countries and that the patterns are crucially influenced by the evolving demographic structures in the respective countries. While we offer a cross-country comparison for such variables shortly, it is at the natural derivation of this observation that we relate demographic changes to the economic growth in post-reform India, which currently appears to be at its prime in terms of the demographic resources. In our attempt to investigate and highlight the elemental causes behind the demography-to-growth relation, the role of public expenditures on three main 
items of interest have been studied in detail. These are: public expenditures on health, on education and on infrastructure.

At the cross-country level (see Cooper, 2015; Fanelli, 2015; etc.), asymmetric demographic changes associated with changes in factor flows and internal policies have influenced higher growth rates in some of the South countries over a considerably long phase. The so-called first and second demographic dividends seem to have significantly facilitated the outcomes. In an increasingly integrated global system of production and factor flows, gains from economic growth (and losses from downturns) are rarely restricted to one country alone. Notwithstanding, the benefits (or losses) may not spread evenly across countries unless the economy under consideration displays capacity to absorb or dispel temporary shocks. The evolution of the demographic structure is one such factor that can (conditionally) facilitate preponderance of positive shocks in economic growth.

The plan of the paper is as follows. In section 1.1, we offer the important macroeconomic and financial characterizations for India in comparison to other emerging economies in order to obtain a relative picture. The comparison is based on population growth as the prime driver of what we strive to understand in this study, namely the importance and role of demographic dividend in influencing economic growth. We also look at the savings pattern, the investment patterns, trading in stock exchanges as an indicator of financial width, trade patterns and capital inflows all as part of the GDP, essentially to motivate the macroeconomic model dealing with fiscal expenditures in relevant categories. The subsequent econometric exercise estimates the crucial parameters of the model.

Note that, the analytical and the empirical exercises conducted in this paper do not engage with estimating the growth impetus arising from financial and other factors as described above (see, Das and Kar, 2015). Instead, we focus on the impact of public 
expenditure in specific categories on the rate of change of economic growth in India, when demographic change plays a crucial supporting role. Section 1.2 offers a detailed discussion on demographic dividend for India.

A review of the literature reveals that studies in this area are generally scant, and especially so for India. Although there are many studies pertaining to demographic transition and economic development in India, they do not address inter-linkages with public goods and generally public expenditure in important categories. ${ }^{1}$ We develop a simple extension of the endogenous model of growth in section 2 and discuss the implications of changes in the size of the working population as a proxy for the demographic dividend that the country is experiencing. In the said model, the principal categories of expenditure are public expenditures on health and education, which helps to generate stocks of 'health capital' and 'education capital' as arguments of the economy-wide production function. The main objective of the model is to obtain a steady-state growth path in the spirit of the Solow models, but by endogenizing the equilibrium configurations of health and education expenditures in the economy. The demographic change is expected to affect the growth path under plausible conditions. In section 3, we conduct an econometric exercise to observe the relation between expenditures in health, education, infrastructure and economic growth. Section 4 concludes with policy recommendations.

\subsection{A cross-country comparison}

Viewed over a reasonably long period of time, one may clearly observe that the GDP growth rate for China had already risen to $15 \%$ by 1984 shortly after the economic

\footnotetext{
1 For example Dyson (2008) offers a comprehensive survey on the general issues of demography and development process in India. See also Visaria (2009), Devika (2008), Thapa et al. (2012), James and Subramanian (2003), etc.
} 
transformation had begun in the country by the end of the decade of the 1970's (Figure 1.1).

Brazil, India and South Africa registered moderate to low growth rates at the time and seemed to emulate the less than $5 \%$ growth rate characteristics of the developed world per se. The differences between these countries are obviously many. Of these, the economic bases and the demographic patterns could be quite important in explaining the major gaps in the observed growth rates. While we focus on the major drivers of growth in India next, presently let us explore a few other broad indicators for countries with comparable growth performances.

Figure 1.1 GDP Growth Rates for Brazil, China, India and South Africa

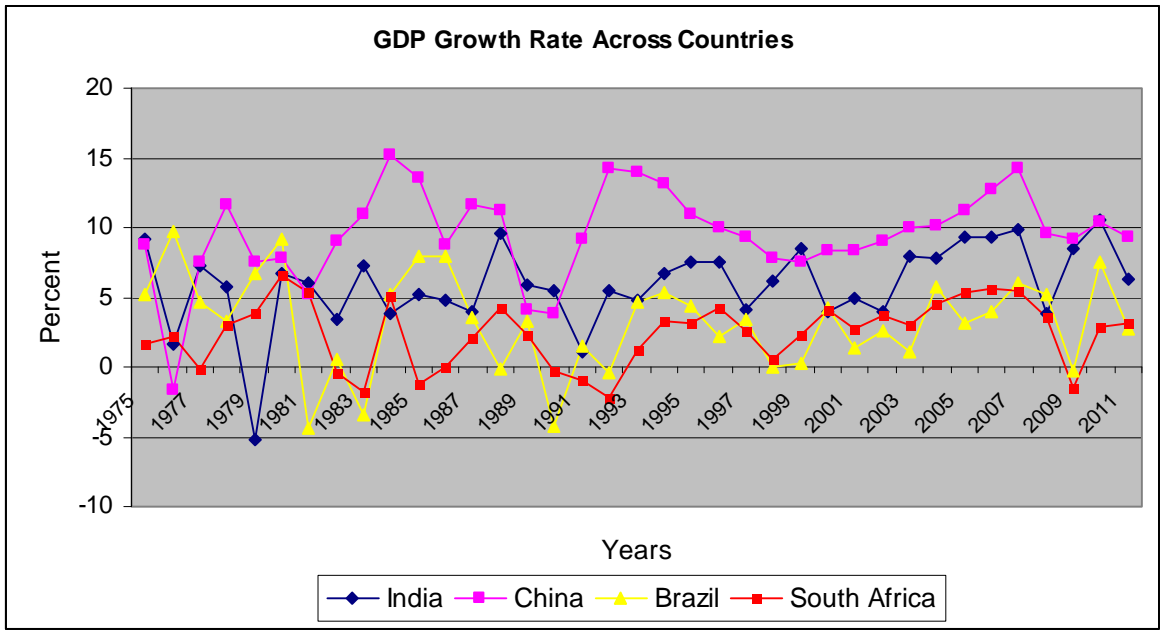

Source: WDI, World Bank

Figure 1.2. $\quad$ Dependency Ratios in Brazil, China, India and South Africa

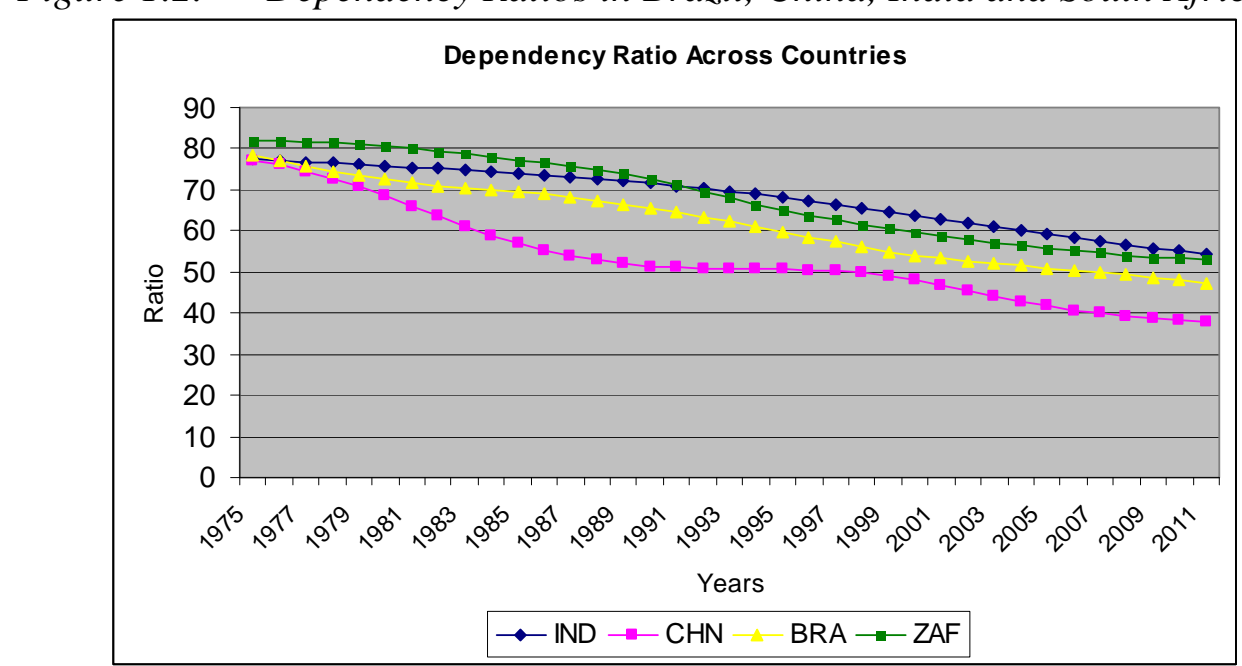

Source: WDI, World Bank 
Figure 1.2 for example, shows that the dependency ratio for these countries have been going down steadily over time - a characteristics associated with the rising share of 15-64 year old population in these countries. For china, the ratio has gone down to 40, while those for the other three countries are still at 50. This is commensurate with Figure 1.3, where the population growth rate for China is at the minimum (0.5\%) in the recent times. Both Brazil and India showed steady decline over time from close to $2.5 \%$ down to less than $1 \%$ and 1.5\% respectively. Note however, that during the recent years (2001) and even earlier (198188), South Africa registered more than $2.5 \%$ growth rate in its population. Since the base population is already high for both China and India, it is expected that the demographic dividends might be more for these countries, provided adequate opportunities through human capital developments, access to economic and financial activities present themselves.

Figure 1.3 Population growth rates in Brazil, China, India and South Africa

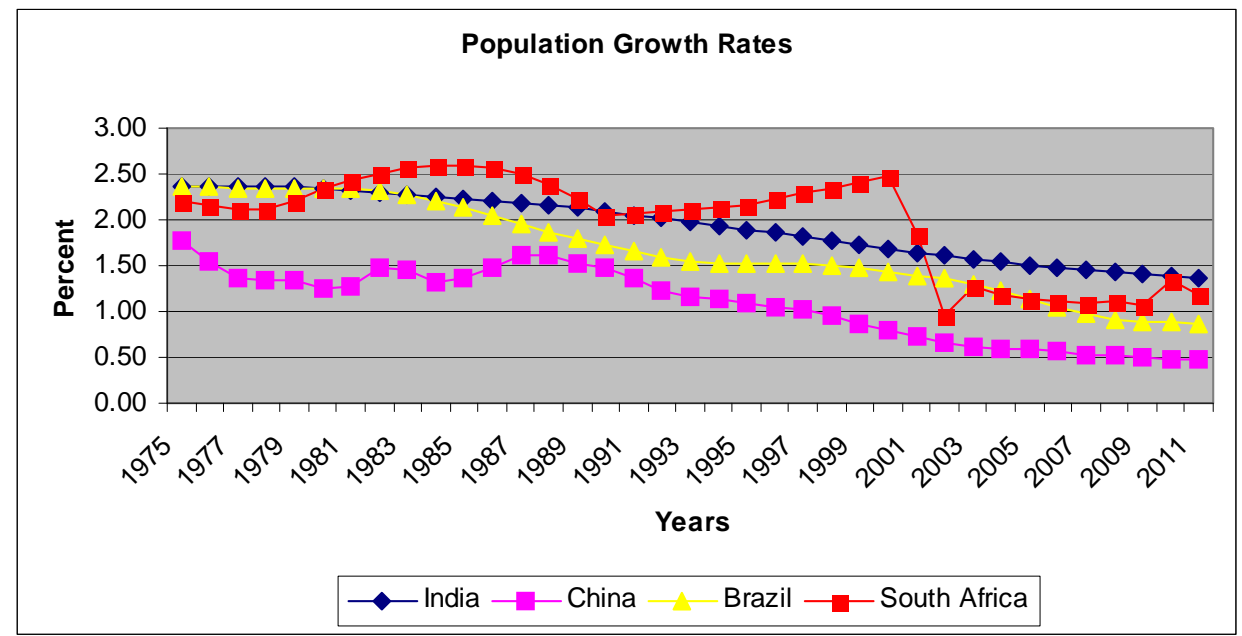

Source: WDI, World Bank

In this connection, figure 1.4 suggests that South Africa and China, both have been able to create appropriate credit facilities to its population at fairly high percentages, much above that available for Brazil and India over the last two decades. However, it must be 
acknowledged that the availability of and access to credit is also rising in the other countries, while it has either reached a plateau or started going down for China and South Africa.

Figure 1.4 Domestic Bank Credit as \% of GDP

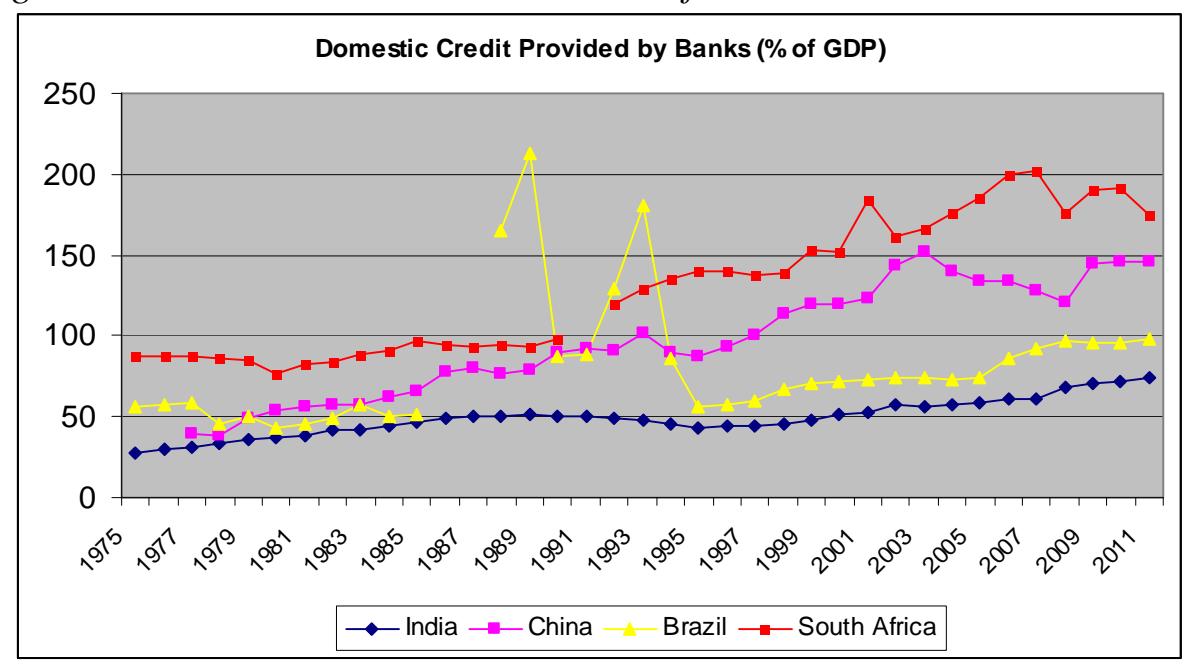

Source: WDI, World Bank

It should also be noted that the outreach of the financial sector and the instruments of investments available thereof are in much better shape at least as far as the stock market activities of the countries like Brazil, China and India are concerned. Of these, India seems to be trading larger amounts in stocks and after a peak in the year 2000 (same as China) the

Figure 1.5 Total Value of Stocks Traded in Brazil, China and India

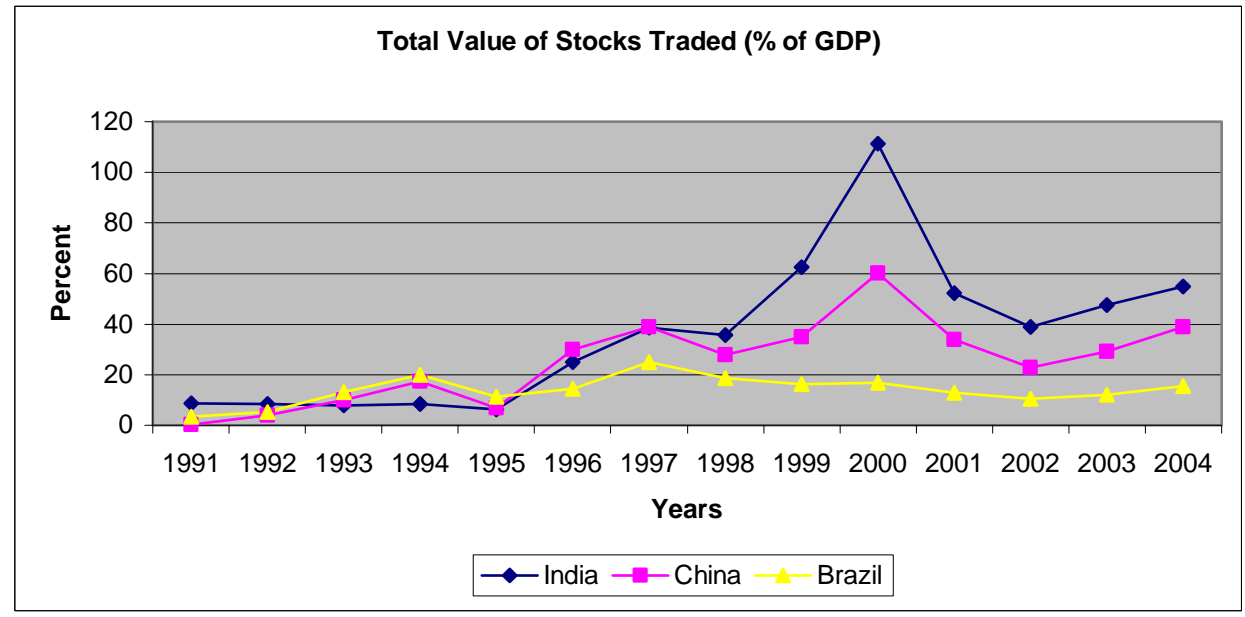

Source: WDI, World Bank.

value is at a considerably high level of $60 \%$ of GDP. These are suggestive of financial depth and vibrancy for a country in need of many other interventionist policies to rise to the level of 
the developed world. Brazil, for example needs to attract more stock market activities raising the level from a low 20\% of its GDP. Interestingly, during the same period India, Brazil and South Africa have leapfrogged significantly to the world of service sector related activities. In fact, India's share of service sector in its GDP has gone up all the way to more than $50 \%$ (figure 1.7) and in terms of the trade in services, India (at 8\% of GDP by 2004, figure 1.6) is also doing better compared to both Brazil and China. China, as it is well known, developed a strong industrial sector with the help of huge capital inflows of foreign origin. These and subsequent matters form the core of our discussion in the following sections with the focus exclusively on India. Table 1.1 for example shows the population in 15 major cities in India according to the Census of India (2011).

Figure 1.6. Trade in Services as \% of GDP

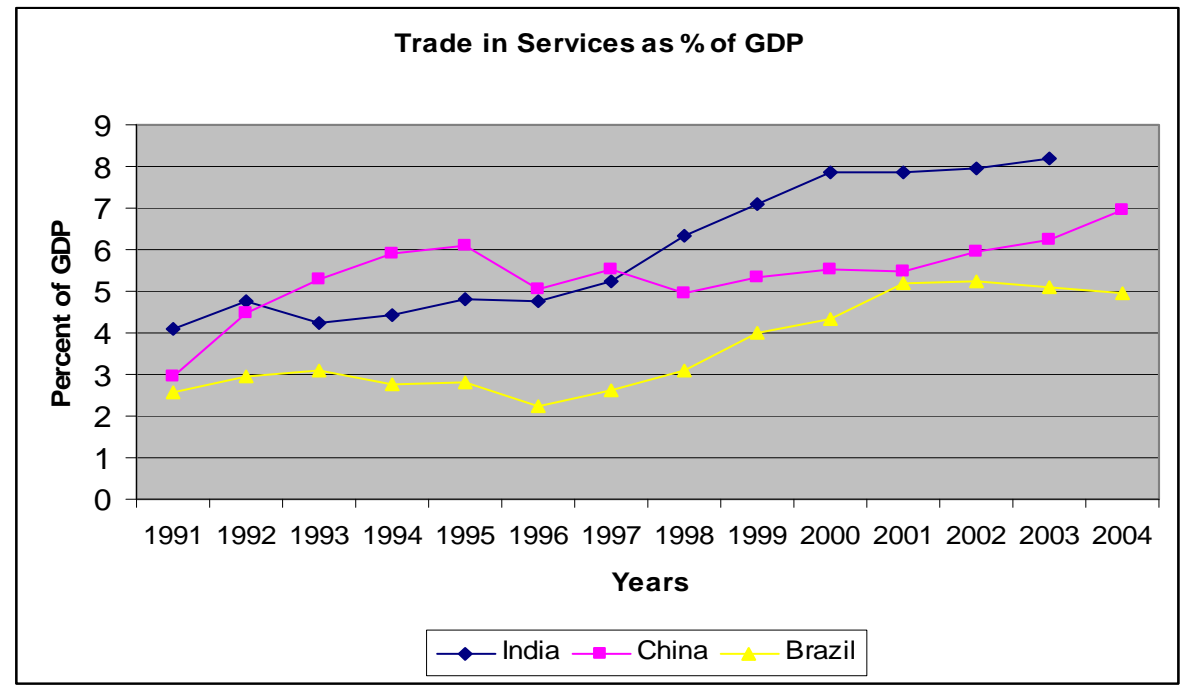

Source: WDI, World Bank.

Note further that the inflow of northern capital seeking higher per unit return on every dollar invested is one of the major activity components of the sprawling service sector. The growth of financial intermediaries and the development of a well functioning financial market are facilitators of these complex interactions. The government policies had always been 
instrumental for the development of infrastructure, health, education capital and the financial institutions and markets in some of the countries. India, like South Korea followed a system of interventionist government policies in the form of directed credit program, differential interest rates etc. Burgess and Pande (2005) report the positive impact of licensing policy on the spread of branch expansion on growth and poverty reduction during the post bank nationalization era in India, mainly up to early 1990 s.

Figure 1.7 India's Share of Service Sector in GDP

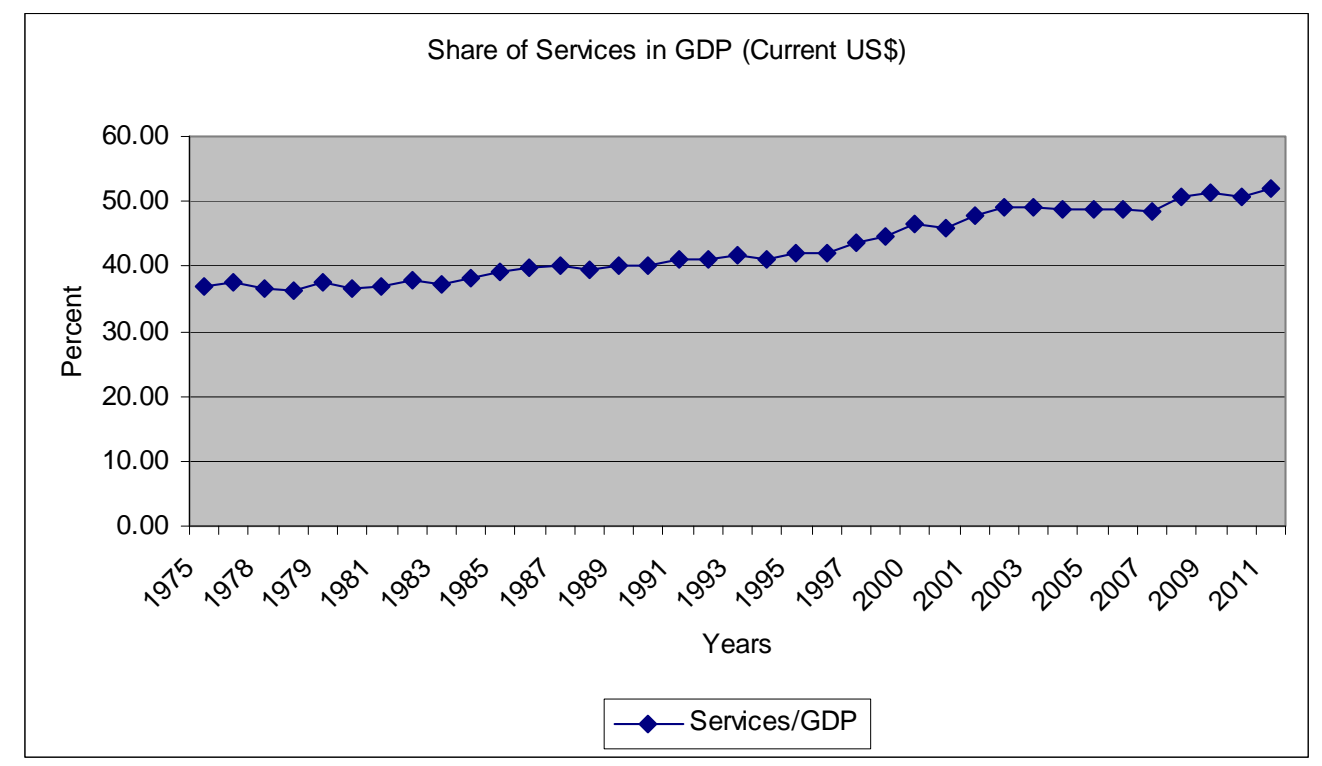

Source: Reserve Bank of India, Handbook of Statistics on Indian Economy

\subsection{Demographic Dividend}

At this point, let us elaborate briefly on what the first and second demographic dividends imply for India. An expected rise in India's demographic dividend means that the country's dependency ratio, as measured by the share of the young and the elderly as a fraction of the population, will come down more sharply in the coming decades. Increase in the share of working age population means more workers in the productive age groups that will add to the total output, generate more savings, accrue more capital per worker, and all 
these leading to higher economic growth. It is expected that since demographic change is associated with decline in fertility, the transition shall be accompanied by greater female participation in the labor force. According to the Population Census 2011 figures, the total population in India is 1.21 billion, which is expected to rise up to 1.40 billion by 2026 mainly owing to an increase in life expectancy at birth for males and females from 65.8 and 68.1 years, respectively. These figures reported between 2006 and 2010 shall rise up to 69.8 and 72.3 years respectively during 2021-2025. Second, a decline in the total fertility rate (TFR) from 2.6 to 2.0 is the main initiator of demographic dividends, such that the fall in TFR with older generations having shorter life expectancies, the dependency ratio declines dramatically. The overall transition is responsible for the demographic dividend of a country. The implications of the demographic transition on age structure are further evident for the population below 20 years, for which the share in total population went down from 51\% in 1970 to $41 \%$ in 2010 and may further decline to $22 \%$ in 2050 . During the same period, the share of the total population under age 60 marginally increased from 5.5\% to $8 \%$. This will obviously rise and is expected to reach $22 \%$ in 2050 . The large decline in the share of the population under 19 years of age has been associated with a substantial rise in the proportion of the working-age population (19-59 years) from 43\% to 51\% between 1970 and 2010 and is forecasted at a maximum of 56\% by 2045 .

Within India, not surprisingly, the distribution of population growth has been asymmetric. The rural population in India is still around 68\% of the total population (Census of India, 2011), whereas, the urban population pattern is somewhat similar to comparable countries. Nevertheless, the windows of opportunities are proportionately more concentrated in the urban areas and one would expect that dwindling prospects in agriculture shall perpetuate the rural-urban migration as characterizing the path of development for the last 
several decades. The interface between the financial systems as a whole, access to more productive economic activities and the population distribution therefore needs a reevaluation.

Viewed over a three-decade horizon, the GDP growth rate in India hovered between 9\% way back in 1977 to negative and fairly low growth rates for most parts of the decade of the 1980 s. In the post-reform period, while the country grew at $6 \%$ rate in most years, by the year 2000 it crossed the $8 \%$ mark and despite $4 \%$ growth rates in the following three years it went up to $8 \%$ once again in 2004, and subsequently grew at 9\% and 10\% rates until 2009 when the onset of global recession dropped it back to 4\%. Nevertheless, and somewhat contrary to the global trend, India registered more than $10 \%$ growth even for 2011 , beyond which however, the rate of growth caved in with revised estimates at 5.2\% in 2013 .

Figure 1.8 Real GDP Growth Rate for India: 1975-2012

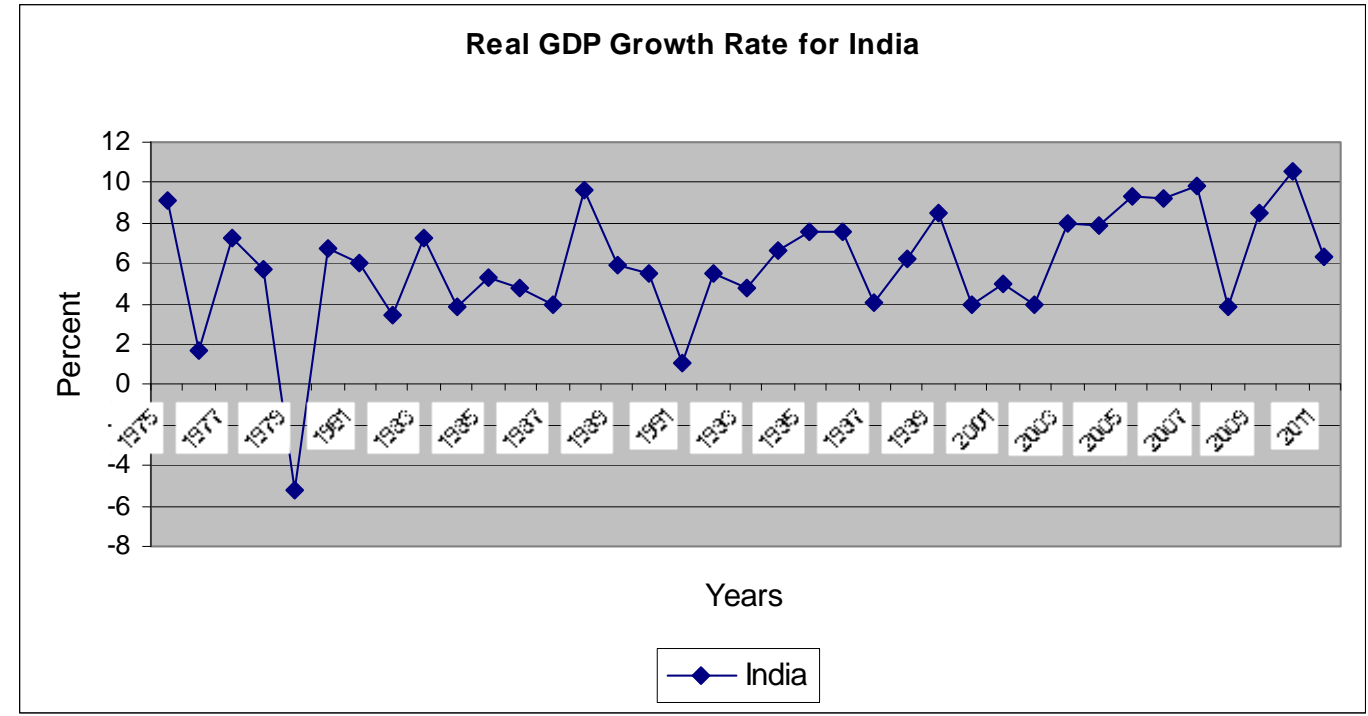

Source: WDI, World Bank.

Note that, the focus of the present paper is about the demographic transition in India and its relation to the financial and economic patterns that emerged over time. Figure 1.9 
shows that the dependency ratio (defined as, $\left[100-\frac{\text { working poulation }}{\text { Total Population }} \times 100\right]$ ) for India has been going down steadily over time - a characteristic associated with the rising share of 1559 year old population (see Albrieu and Fanelli, 2012 for cross country comparison and analysis). Since the base population is already high for both China and India, it is expected that the demographic dividends might be more for these countries, provided adequate opportunities through human capital developments, access to economic and financial activities present themselves. Importantly, the dependency ratio for India has come down to 50 in the year 2012.

Figure 1.9 Dependency Ratio for India: 1975-2012

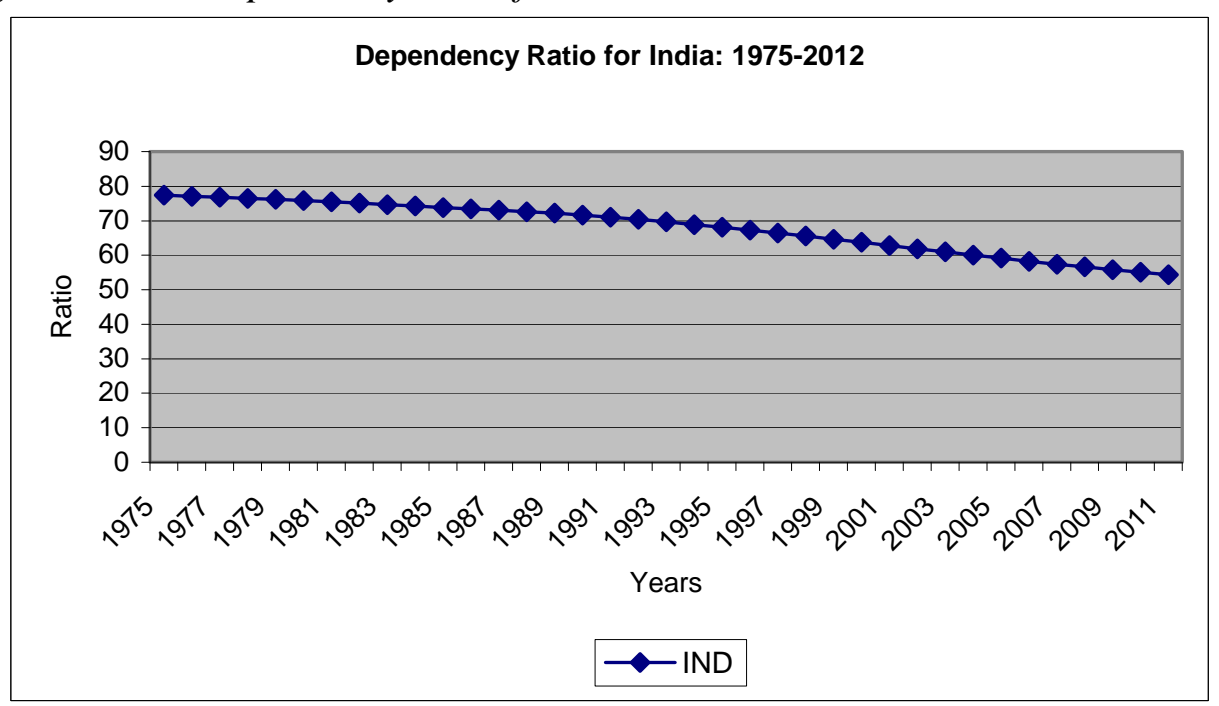

Source: WDI, World Bank

We have discussed it in the beginning that the population growth rate, after the long phase of 2.5 to $2 \%$ until 1990 s, went below $2 \%$ for the first time in 1993 . The downward trend has continued since then close to $1.5 \%$ in 2012 . The population growth rate is still sufficiently high (with significant urbanization and improvement in literacy rates, see Table 1.1) to expect that high rate of entry into the workforce shall continue even for the medium run such that the ageing population could be supported via transfers. 
Figure 1.10 The Population growth rate in India

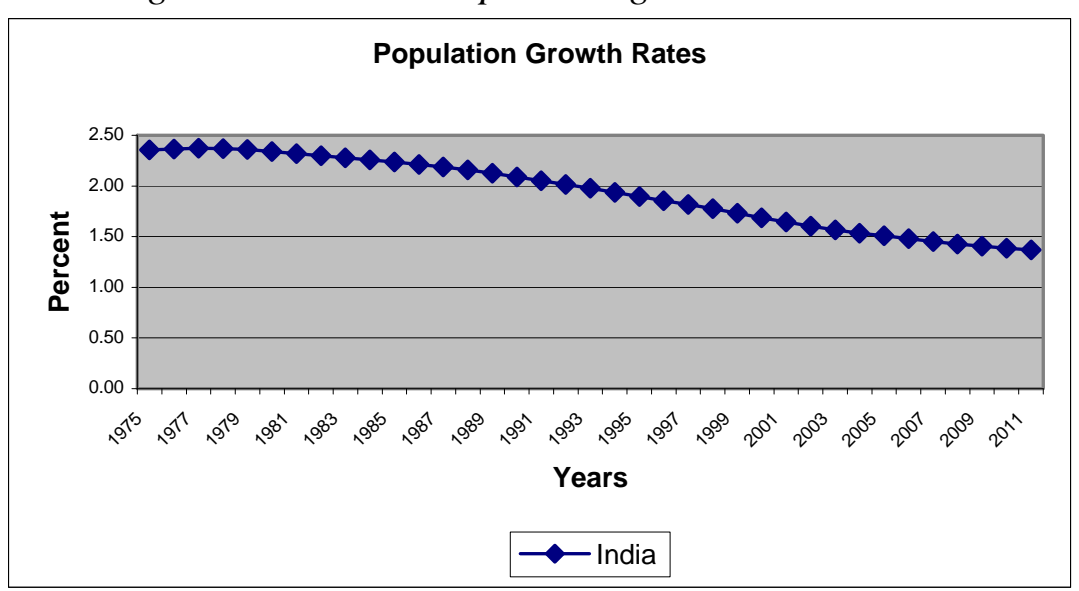

Source: WDI, World Bank

The relevance of the economic and financial institutions is unmistakable in such an environment. The bank based financial system in India shall bestow greater dependence on the credit and allied facilities that the potential entrepreneurs and employees shall access at an increasing rate. Figure 1.11 suggests that the domestic credit facility in India has risen from a meager 25\% in 1975 to almost 75\% in 2012, which given the GDP of India is considerably large.

Figure 1.11 Domestic Bank Credit as \% of GDP

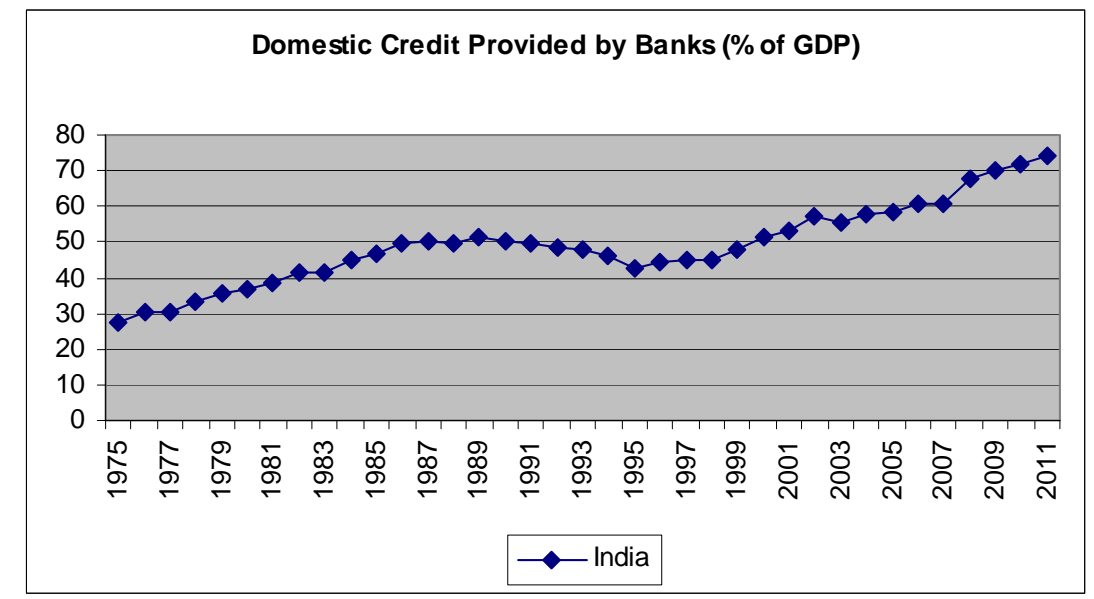

Source: WDI, World Bank 
Table 1.1 Table Showing Urban Population in Top 15 Cities in India

\begin{tabular}{|c|c|c|c|c|c|c|}
\hline Sr. No. & City Name & State & City & $\begin{array}{c}\text { State Urban } \\
\text { Pop }\end{array}$ & Sex ratio & Literacy \\
\hline 1 & Mumbai & Maharashtra & 12478447 & 18414288 & 852 & 90.28 \\
\hline 2 & Delhi & Delhi & 11007835 & 16314838 & 875 & 87.6 \\
\hline 3 & Bangalore & Karnataka & 8425970 & 8499399 & 914 & 89.59 \\
\hline 4 & Hyderabad & Andhra Pradesh & 6809970 & 7749334 & 945 & 82.96 \\
\hline 5 & Ahmedabad & Gujarat & 5570585 & 6352254 & 897 & 89.62 \\
\hline 6 & Chennai & Tamil Nadu & 4681087 & 8696010 & 986 & 90.33 \\
\hline 7 & Kolkata & West Bengal & 4486679 & 14112536 & 899 & 87.14 \\
\hline 8 & Surat & Gujarat & 4462002 & 4585367 & 758 & 89.03 \\
\hline 9 & Pune & Maharashtra & 3115431 & 5049968 & 945 & 91.61 \\
\hline 10 & Jaipur & Rajasthan & 3073350 & 3073350 & 898 & 84.34 \\
\hline 11 & Lucknow & Uttar Pradesh & 2815601 & 2901474 & 915 & 84.72 \\
\hline 12 & Kanpur & Uttar Pradesh & 2767031 & 2920067 & 842 & 84.14 \\
\hline 13 & Nagpur & Maharashtra & 2405421 & 2497777 & 961 & 93.13 \\
\hline 14 & Indore & Madhya Pradesh & 1960631 & 2167447 & 921 & 87.38 \\
\hline 15 & Thane & Maharashtra & 1818872 & 1818872 & 882 & 91.36 \\
\hline
\end{tabular}

Source: Census of India, 2011

\section{A Model with Health and Education Capital}

Consider a simple model of economic growth in a country endogenously

determined by expenditures incurred by the state on two important factors, namely, health $(H)$ and education $(E)$. The model uses two sets of assumptions. First we assume that income $(Y)$ is a multiplicative function of expenditures incurred on $H(t)$ and $E(t)$ and the quantity of effective labor $A(t) L(t)$ all at time ' $t$ '. Second, we will assume that 'production' of health and education follow simple functional forms (see Campodonico, Casinelli and Mesones, 2014; 
Hokayena nd Ziliak, 2014; Arthur, 2013; Gyimah-Brempong and Wilson, 2004; Knowles and Owen, 1997; Grossman, 1972; Grossman, 1972, etc), such that the outcome of public expenditure translates into stocks of health and education capital for the economy. If the state expends $H_{g}(t)$ amount of revenue (we do not model the tax issue) on health it helps to generate $H(t)=\left[H_{g}(t)\right]^{1 / \beta}, 0<\beta<\infty$ number of individuals with health capital. The stock thus generated supports production of $Y(t)$. The other form of human capital arises from public expenditure on education, $E_{g}(t)$ and equivalently produces stock of educated workers, $E(t)=\left[E_{g}(t)\right]^{1 / \alpha}, 0<\alpha<\infty$. In other words, \$x amount of expenditure in say health, produces $x^{1 / \beta}, 0<\beta<\infty$, units of health capital and comparably for education capital. For $\beta \rightarrow \infty$, the one-dollar expenditure is magnified, meaning it produces a large number of individuals with health capital. Formally, the health outcome is a function of $H_{g}(t)$ as the health-related expenditure, $\underline{G}(t)$ as the vector of health system variables, such as the extent of vaccination, frequency of endemic diseases, availability of hospitals, etc. and $\underline{X}(t)$ as the vector of socio-economic variables including population structure, average education level in the economy, etc. making public expenditure itself an endogenous outcome. Presently, we assume that at given levels of all these variables, the stock of health capital available in the economy at time $t$ is $H(t)$. This is analogous to the impact of education-related expenditure on the production of the stock of human capital in the economy. Thus, the economy-wide output is given by,

$$
Y(t)=\left[H_{E}(t)\right]^{\frac{\phi}{\beta}}\left[E_{E}(t)\right]^{\frac{\eta}{\alpha}}[A(t) L(t)]^{1-\left(\frac{\phi}{\beta}+\frac{\eta}{\alpha}\right)}, 0<\alpha, \beta<\infty, \phi>0, \eta>0,\left(\frac{\phi}{\beta}+\frac{\eta}{\alpha}\right)<1
$$

$A(t) L(t)$ in equation (1) is defined as the effective labor. Equation (1) follows a generalized 
Cobb Douglas production function $Y(t)=F(H, E, A L)$ with constant returns to scale and satisfies the two-variable analog of the Inada condition. The technological progress is considered exogenous and it is invariant for production of new knowledge through education and health related attributes as inputs in production. Note that, we assume $\beta>\phi$ and $\alpha>\eta$. What does it imply? It means that the impact of public expenditure on health (education) outcome is stronger than the impact of adding one more unit of health (education) capital on growth (see Arthur, 2013). It may apply fairly well to developing countries, where public expenditure if properly targeted and the program suitably implemented, generates a strong outcome on the beneficiaries but an expansion of that stock of beneficiaries does not necessarily translate to corresponding economic outcomes due to prevalence of various frictions in the economy. ${ }^{2}$

The usual assumptions of the Solow model (see Romer, 1996) regarding the share of physical capital devoted to production of output can be supplanted by the share of expenditures on health $\left(s_{H}\right)$ and education $\left(s_{E}\right)$ that leads to a change in the stocks as per above specifications in the following way:

$$
\begin{aligned}
& \dot{H}(t)=s_{H} Y(t) \\
& \text { and } \quad \dot{E}(t)=s_{E} Y(t) \\
& \text { where } \dot{H}(t)=\frac{d H(t)}{d t} \text {, for example. We also assume } \\
& \dot{L}(t)=n L(t) \\
& \dot{A}(t)=\rho A(t)
\end{aligned}
$$

\footnotetext{
${ }^{2}$ Frictions in the labor market (Gutierrez, et al. 2010) or in the financial market (Itskhoki and Moll, 2014) continue to be of serious magnitude affecting the growth potential in many developing countries.
} 
where, $n$ is exogenous growth of population (for want of annual data on population growth, we shall consider this as the exogenous growth of labor force participation for the empirical exercise) and $\rho>0$ is the rate of exogenous technical progress. The above assumptions clearly display that the model is an extension of the Solow model, where the health and education capital replaces the physical capital for a standard endogenous growth model. We will consider the dynamics of both education and health capital as two distinct components of human capital per unit of effective labor. In particular, we begin by defining, $y(t)=\frac{Y(t)}{A(t) L(t)}, h(t)=\frac{H(t)}{A(t) L(t)}$ and $e(t)=\frac{E(t)}{A(t) L(t)}$. These are standard textbook assumptions modified to look into (i) the dynamics of $h(t)$ and $e(t)$; (ii) for obtaining the levels of $h(t)$ and $e(t)$ essential for achieving a steady-state growth path; and (iii) depict the changes in the steady-state growth path when the important parameters of this model, including labor force participation changes. The above formulations lead to

$$
y(t)=[h(t)]^{\frac{\phi}{\beta}}[e(t)]^{\frac{\eta}{\alpha}}
$$

Equation (6) is now reduced to two components of public expenditure per unit of effective labor. Beginning with the dynamics of $h(t)$, we differentiate $h(t)=\frac{H(t)}{A(t) L(t)}$ with respect to time, use equations (4) and (5) and get,

$$
\dot{h}(t)=\frac{\dot{H(t)}}{A(t) L(t)}-\frac{H(t)}{A(t) L(t)}(n+\rho)
$$

Using (2) and (3), we get, $\dot{h}(t)=\frac{s_{H} Y(t)}{A(t) L(t)}-(n+\rho) h(t)$

Or, $\quad \dot{h}(t)=s_{H} y(t)-(n+\rho) h(t)$

Using (6) $\dot{h}(t)=s_{H}[h(t)]^{\frac{\phi}{\beta}}[e(t)]^{\frac{\eta}{\alpha}}-(n+\rho) h(t)$ 
The growth of health capital over time is zero for this economy, if $\dot{h}(t)=0$. This implies, $s_{H}[h(t)]^{\frac{\phi}{\beta}}[e(t)]^{\frac{\eta}{\alpha}}=(n+\rho) h(t)$, from which we can find out a combination of $h(t)$ and $e(t)$ in the $\{e, h\}$ space in order to trace the dynamic characteristics of $h(t)$. Here,

$$
h(t)=\left(\frac{s_{H}}{n+\rho}\right)^{\frac{\beta}{\beta-\phi}}[e(t)]^{\frac{\beta \eta}{\alpha(\beta-\phi)}}
$$

The first-order condition from (8) provides,

$$
\frac{\delta h(t)}{\delta e(t)}=\left(\frac{s_{H}}{n+\rho}\right)^{\frac{\beta}{\beta-\phi}}\left(\frac{\beta \eta}{\alpha(\beta-\phi)}\right)[e(t)]^{\frac{\beta \eta}{\alpha(\beta-\phi)}-1}
$$

From (8a), since $\beta>\phi, \frac{\delta h(t)}{\delta e(t)}>0$. Further, since $\left(\frac{\phi}{\beta}+\frac{\eta}{\alpha}\right)<1$, the second order is negative. From the second-order condition $\left(\frac{\beta \eta}{\alpha(\beta-\phi)}-1\right)<0$ implies $\left(\frac{\phi}{\beta}+\frac{\eta}{\alpha}\right)<1$.

Thus, the second-order derivative of (8a) along the locus gives a concave relation. As discussed earlier, the impact of health expenditure on stock of healthy workers and the stock of workers with health capital on growth is positive but decreasing over time. To the right of the $\dot{h}=0$ locus, $\dot{h}$ is positive and to the left it is negative. Any $h(t)$ at a given

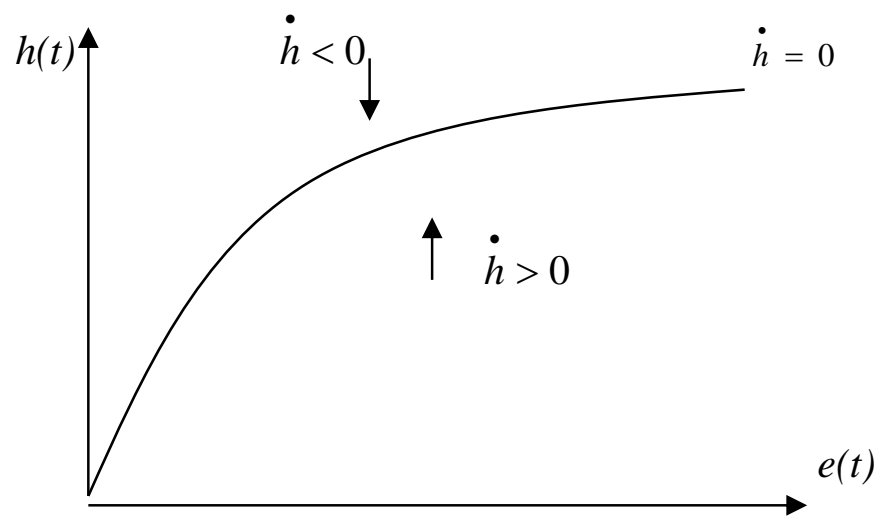

Figure 2.1. The dynamics of health capital per unit of effective labor 
$e(t)$ lower than that which maintains $\dot{h}=0$ must raise $\dot{h}$ and vice versa. As long as the impact of stock of healthy workers on the growth is lower than this, our results have merit. It nonetheless remains an empirical exercise to verify the case for India. Available empirical estimates (viz. Arthur, 2013 for Sub-Saharan Africa) show that $\beta$, if life expectancy is treated as an outcome, is about 0.013 . As alternative outcomes, per capita public health expenditure lowers infant mortality by about $6 \%$ and under-five mortality rate by about $7 \%$.

Next, we consider the dynamics of $e(t)$. Following the same procedure as above,

$$
\dot{e}(t)=s_{E}[h(t)]^{\frac{\phi}{\beta}}[e(t)]^{\frac{\eta}{\alpha}}-(n+\rho) e(t)
$$

Once again, we express $h(t)$ and $e(t)$ in the $\{e, h\}$ space, where holding $\dot{e}(t)=0$ leads to,

$$
e(t)=\left(\frac{S_{E}}{n+\rho}\right)^{\frac{\alpha}{\alpha-\eta}}[h(t)]^{\frac{\phi \alpha}{\beta(\alpha-\eta)}}
$$

Conducting $\frac{\delta h(t)}{\delta e(t)}$ in the $\{e, h\}$ space, we get,

$$
\frac{\delta h(t)}{\delta e(t)}=\left(\frac{n+\rho}{s_{E}}\right)^{\frac{\beta}{\phi}}\left(1-\frac{\eta}{\alpha}\right) \frac{\beta}{\phi}[e(t)]^{\frac{(\alpha-\eta)}{\alpha}-\frac{\beta}{\phi}}-1
$$

From (10a), as $\alpha>\eta$ by prior assumption, the first order is positive. Importantly, the secondorder is also positive along the $\dot{e}(t)=0$ locus. The positive second-order derivative requires that $\left(\frac{(\alpha-\eta) \beta}{\alpha \phi}-1\right)>0$, i.e., $\left(1-\frac{\eta}{\alpha}>\frac{\phi}{\beta}\right)$ or $\left(\frac{\phi}{\beta}+\frac{\eta}{\alpha}\right)<1$. Therefore, in the $\{e, h\}$ space, $\dot{e}(t)=0$ generates the following dynamic pattern. 


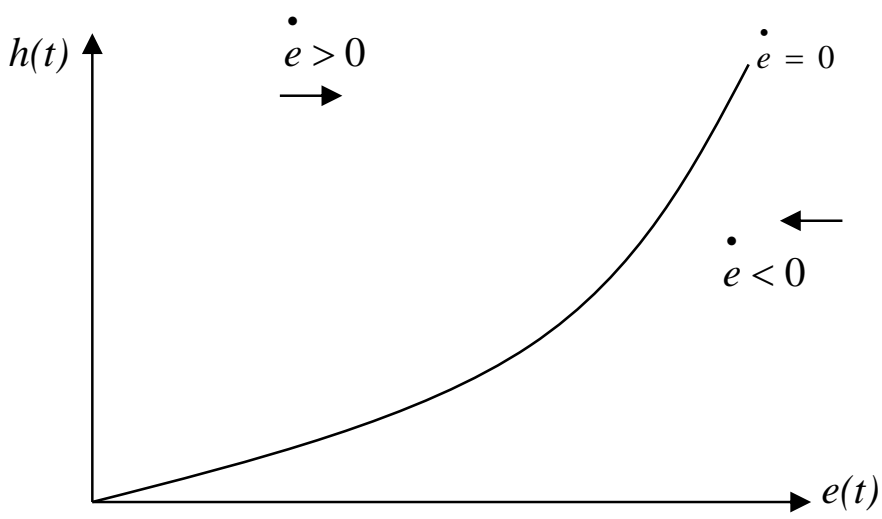

Figure 2.2. The dynamics of education capital per unit of effective labor

To the right of the $\dot{e}=0$ locus, $\dot{e}$ is negative and to the left it is positive. Any $e(t)$ at a given $h(t)$ lower than that which maintains $\dot{e}=0$ must raise $\dot{h}$ and vice versa. In this framework, the initial values of $H, E$, $A$ and $L$ determine the initial levels of $h(t)$ and $e(t)$ in the steady-state equilibrium. Putting figures 2.1 and 2.2 in the same diagram yields a globally stable equilibrium at point $M$. The equilibrium suggests that starting from any point in the $\{e, h\}$ space, the economy arrives at $M$ and stays there unless there is a change in expenditure shares incurred on health or education as fraction of GDP per capita. These constitute the crucial elements in the empirical model in the next section.

However, let us trace the impact of a change in ' $n$ ' treated as the working age population, on the steady state. Intuition suggests that when the economy's effective labor force grows and the labor market participation rises, it should affect both $h(t)$ and $e(t)$ as evident from equations (8) and (10). The demographic change and expansion of labor force is expected to have an impact analogous to an exogenous rise in technical progress. The nature of the shift should be conditional on the strength of the parameters and should offer an empirically testable hypothesis. 


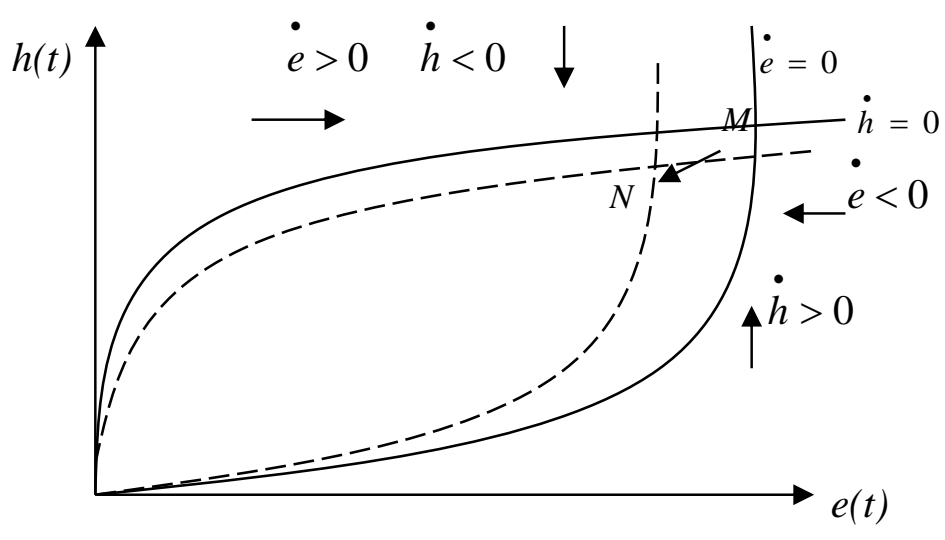

Figure 2.3. The dynamics of health and education capital

It should be noted that a secular rise (decline) in ' $n$ ' would negatively (positively) affect both ( $\dot{h}=0 ; \dot{e}=0)$ from equations (7) and (9) respectively. In terms of the equilibrium, Figure 2.3 shows that as 'n' rises, both $(\dot{e}=0 ; \dot{h}=0)$ shift in and converge at a new equilibrium $N$, instead of the initial point of convergence at $M$. As ' $n$ ' rises, it affects growth of health stock and education stock negatively. As $\dot{h}=0$ shift inward, at a given $e(t), h(t)$ falls below $\dot{h}=0$. The new health capital growth curve intersects the education growth curve below $M$, the initial steady-state growth path of the economy. Here, as the economy shifts down to a lower growth path, $e(t)$ starts falling as well. The net effect is, however, much stronger, since a fall in ' $\mathrm{n}$ ' shifts $e(t)$ inward as well. The final equilibrium may settle at a point like $N$, where the economic growth path is substantially lower. So, the challenge here is to see if the rise in ' $n$ ' with its effect on $h(t)$ and $e(t)$ can lead to a higher trajectory for the economy.

Consider the equilibrium where, $h(t)=e(t)$ in the $\{e, h\} \in[0, \infty)$ space at the point of convergence of $(\dot{e}=0 ; \dot{h}=0)$. Using (7) and (9), we get, 


$$
s_{H}[h(t)]^{\frac{\phi}{\beta}}[e(t)]^{\frac{\eta}{\alpha}}-(n+\rho) h(t)=s_{E}[h(t)]^{\frac{\phi}{\beta}}[e(t)]^{\frac{\eta}{\alpha}}-(n+\rho) e(t)
$$

Reformulating, $[e(t)-h(t)](n+\rho)=\left(s_{E}-s_{H}\right)[h(t)]^{\frac{\phi}{\beta}}[e(t)]^{\frac{\eta}{\alpha}}$

Differentiating equation (11) fully, we get,

$$
\begin{aligned}
& {[d e(t)-d h(t)](n+\rho)+(d n+d \rho)[e(t)-h(t)]} \\
& \quad=\left(d s_{E}-d s_{H}\right)[h(t)]^{\frac{\phi}{\beta}}[e(t)]^{\frac{\eta}{\alpha}}+\left(s_{E}-s_{H}\right)\left[e(t)^{\frac{\eta}{\alpha}} \frac{\phi}{\beta}[h(t)]^{\frac{\phi}{\beta}-1} d h(t)+[h(t)]^{\frac{\phi}{\beta}} \frac{\eta}{\alpha} e(t)^{\frac{\eta}{\alpha}-1} d e(t)\right]
\end{aligned}
$$

Considering $d \rho=d s_{E}=d s_{H}=0$, the above expression changes to,

$$
[e(t)-h(t)]=\left(s_{E}-s_{H}\right)\left[\frac{\phi}{\beta} \frac{1}{\tilde{h}(t)} \frac{d h(t)}{d n}+\frac{\eta}{\alpha} \frac{1}{\widetilde{e}(t)} \frac{d e(t)}{d n}\right]-(n+\rho)\left(\frac{d e(t)}{d n}-\frac{d h(t)}{d n}\right)
$$

where, $[h(t)]^{\frac{\phi}{\beta}}[e(t)]^{\frac{\eta}{\alpha}}$ is substituted by $y(t)$ from (6). Also, we define $\tilde{h}(t)=\frac{h(t)}{y(t)}$, and $\tilde{e}(t)=\frac{e(t)}{y(t)}$. From (12),

$$
\frac{d h(t)}{d n} / \frac{d e(t)}{d n}>1 \text { iff, } \frac{d h(t)}{d n} / \frac{d n(t)}{d n}=\frac{(n+\rho)-\frac{\left(s_{E}-s_{H}\right)}{\tilde{e}(t)} \frac{\eta}{\alpha}}{(n+\rho)+\frac{\left(s_{E}-s_{H}\right)}{\tilde{h}(t)} \frac{\phi}{\beta}}>1
$$

Thus, $\left[\frac{d h(t)}{d n} / \frac{d e(t)}{d n}\right]>1$, iff, $\left(s_{E}-s_{H}\right)\left[\frac{y(t)}{h(t)} \frac{\phi}{\beta}+\frac{y(t)}{e(t)} \frac{\eta}{\alpha}\right]<0$

This is possible, only if, $\left(s_{E}-s_{H}\right)<0$. In other words, the growth of the labor force unambiguously raises expenditure on health more than that in education, if and only if the initial share of expenditure on education is strictly lower than that in health.

More generally, however, starting from the point where $(\dot{e}=0 ; \dot{h}=0)$ converge, one can show that a rise in 'n' will affect the health outcome more (less) than the education outcome in the following way. From (12), 


$$
\left[\frac{d h(t)}{d n} / \frac{d e(t)}{d n}\right] \frac{\geq}{<} 1, \text { iff, }\left[\left(1-\frac{h(t)}{e(t)}\right) \frac{n}{\sigma_{n}^{e(t)}}+n+\rho\right] \frac{\left(s_{E}-s_{H}\right)}{\widetilde{e}(t)} \frac{\eta}{\alpha}
$$

where, $\sigma_{n}^{e(t)}=\frac{d e(t)}{d n} \frac{n}{e(t)}$ is defined as the elasticity of education expenditure to a change in the rate of growth of population.

Finally, rise in $d s_{E}>0 ; d s_{H}>0$ are expected to have positive effects on the growth path of the economy. In the first case, $(\dot{h}=0)$ is not affected if a greater share of the GDP is spent on education capital, and will only shift $(\dot{e}=0)$ curve to the right. In view of figure 2.3, it should take the growth path of the economy to the northeast of $M$. As $e(t)$ rise along $(\dot{h}=0), h(t)$ also rises and takes the economy to a higher growth path. It suggests that the temporary shock in higher education expenditure helps to land the economy on a level of growth greater than $\rho$ until the new equilibrium is arrived at above point $M$. The new equilibrium shall once again display the same growth rate as before, but in the process helps to take the economy to a higher trajectory. If the stock of health capital rises as well, the process would be repeated and the final growth path of the economy shall situate above $M$ depending upon the relative importance of the outcomes of public expenditure on these dedicated items.

\section{Empirical Model}

For the empirical exercise, we consider five variables, namely, per capita growth rate (Growth_PC), rate of public expenditures on education (Edu_Ratio), health (Health_Ratio) and infrastructure (Infra_Ratio), and the working age population as the proportion of total population (Working_pop). The rates of public expenditure on education and health are sum total of expenditures by both Union and State Governments of India. These expenditures are 
expected to directly affect human capital, while the public expenditure on infrastructure should directly affect the stock of infrastructure in the economy with potential crowding-in effect on private investment. These three variables are expressed as the proportion of GDP and form the set of fiscal variables of interest for the econometric model. More precisely, the public expenditure on infrastructure includes expenditure on energy, transport, communication and irrigation. The data have been collected from publicly available sources, such as the National Accounts Statistics, Central Statistical Organization, Economic Survey, Ministry of Finance, Government of India for the first four and World Development Indicator 2014, World Bank, for data on working age population to total population. It may be noted that the more suitable demographic variable for this study would have been labor force participation. But, as no time series data for this variable is currently available, we settle for working population, instead. This, however, may not be entirely unrealistic in view of the fact that India is passing through the second window of demographic dividends where the share of young workers would be at the maximum. Thus, a growing population would imply a growing labor force. As the unemployment benefit in India is virtually non-existent, the growing labor force often settles for informal and unskilled jobs, with little hope for the benefits of high employment opportunities, high income and high savings feeding into investment and growth to present itself readily. An alternative to this measure is the dependency ratio. We also conducted another macro-econometric exercise with working age population replaced by dependency ratio. The results are by and large similar.

Before the discussion on the macro-econometric exercise, let us first provide the summary statistics of the variables in Table 3.1. Next we checked the non-stationary character of the data. Table 3.2 provides the unit root results for the variables at their levels. 
DF/ADF, Phillips-Perron and KPSS tests for all the variables at their levels are tested positive to exhibit the presence of unit roots both except for per capita growth rate. We also tested for

Table 3.1: Summary statistics: Variables in levels

\begin{tabular}{|l|c|l|l|l|}
\hline & Mean & SD & Min & Max \\
\hline Edu_Ratio & 0.0041 & 0.0013 & 0.0007 & 0.0076 \\
\hline Health_Ratio & 0.0019 & 0.0007 & 0.00107 & 0.0041 \\
\hline Infra_Ratio & 0.0493 & 0.0132 & 0.0264 & 0.0699 \\
\hline working_pop & 59.22 & 2.7606 & 55.41 & 64.76 \\
\hline Growth_PC & 0.03328 & 0.0321 & -0.075 & 0.0802 \\
\hline
\end{tabular}

Table 3.2: Test results for non-stationarity

\begin{tabular}{|c|c|c|c|c|c|}
\hline Variable & \multicolumn{3}{|c|}{ ADF Test: $\mathrm{z}(\mathrm{t})$} & \multicolumn{2}{|c|}{ DF-GLS Test } \\
\hline & Constant & Trend & Drift & $\tau$-Test Statistic & $\mu$-Test Statistic \\
\hline Edu_Ratio & $\begin{array}{c}0.57 \\
(0.987)\end{array}$ & $\begin{array}{l}-1.297 \\
(0.889)\end{array}$ & $\begin{array}{c}0.577 \\
(0.716)\end{array}$ & -1.796 & 0.711 \\
\hline Health_Ratio & $\begin{array}{l}-1.895 \\
(0.33)\end{array}$ & $\begin{array}{c}-1.898 \\
(0.656)\end{array}$ & $\begin{array}{c}-1.895^{* *} \\
(0.03)\end{array}$ & -1.77 & -1.556 \\
\hline Infra_Ratio & $\begin{array}{c}-2.1 \\
(0.246)\end{array}$ & $\begin{array}{l}-1.876 \\
(0.667)\end{array}$ & $\begin{array}{l}-2.1^{* *} \\
(0.02)\end{array}$ & -1.456 & -1.389 \\
\hline Working_pop & $\begin{array}{c}0.41 \\
(0.982)\end{array}$ & $\begin{array}{c}-4.665^{* * *} \\
(0.001)\end{array}$ & $\begin{array}{c}0.41 \\
(0.656)\end{array}$ & $-5.827 * * *$ & -0.517 \\
\hline Growth_PC & $\begin{array}{c}-2.22 \\
(0.199)\end{array}$ & $\begin{array}{c}-4.852 * * * \\
(0.0004)\end{array}$ & $\begin{array}{l}-2.22^{* *} \\
(0.017)\end{array}$ & $-4.167 * * *$ & $-2.283 * * *$ \\
\hline
\end{tabular}

Note: (1) The values in the parentheses are MacKinon approximate p-value.

(2) All the tests were conducted with a lag structure of 3.

(3) For the DF-GLS Test the interpolated critical values are due to Elliot, Rothenberg and Stock (1996).

(4) The critical values of DF-GLS test with 3 lags are $-3.77,-3.19,-2.89$ with trend $(\tau)$ and $-2.636,-1.95,-1.606$ without trend $(\mu)$ statistic at $1 \%, 5 \%, 10 \%$.

Table 3.3: Test results of non-stationarity - Variables in Changes

\begin{tabular}{|l|l|l|l|l|l|}
\hline Variable & \multicolumn{3}{|c|}{ ADF Test, z(t) } & DF-GLS Test & \\
\hline & Constant & Trend & Drift & $\tau$-Test Statistic & $\mu$-Test Statistic \\
\hline$\Delta$ Edu_Ratio & $-5.15 \#$ & -5.545 & -5.15 & -4.83 & -3.728 \\
& $(0.00)$ & $(0.00)$ & $(0.00)$ & & \\
\hline$\Delta$ Health_Ratio & -3.67 & -3.23 & -3.67 & $-3.24^{* * \#}$ & -3.052 \\
& $(0.004)$ & $(0.00)$ & $(.02)$ & & \\
\hline$\Delta$ Infra_Ratio & $-3.80 \#$ & $-4.08 \#$ & $3.79 \#$ & $-3.216^{* * \#}$ & $-2.975^{* * \#}$ \\
& $(0.003)$ & $(0.007)$ & $(0.00)$ & & \\
\hline \multirow{2}{*}{$\Delta$ Working_pop } & $-3.02 \#$ & -4.1 & -2.3 & $-1.402^{* * * \#}$ & 0.087 \\
& $(0.06)$ & $(0.001)$ & $(0.012)$ & & \\
\hline
\end{tabular}

Note: (1) The values in the parentheses are MacKinon approximate p-value.

(2) All the tests were conducted with a lag structure of 2.

(3) For the DF-GLS Test the interpolated critical values are due to Elliot, Rothenberg and Stock (1996).

(4) The critical values of DF-GLS test with 2 lags are $-3.77,-3.19,-2.89$ with trend $(\tau)$ and $-2.636,-1.95,-1.606$ without trend $(\mu)$ statistic at $1 \%, 5 \%, 10 \%$.

(5) \# significant with lag structure of 1. 
structural break using Zivot-Andrews (Zivot and Andrews, 1992) and Lee-Strazicich (Lee and Strazicich, 2001) which both tested for structural break in the presence of unit root. We did not report the results here. However, the same tests at changes of the variables (except per capita growth rate) test for $\mathrm{I}(0)$ as reported in Table 3.3. Since per capita growth are already found to be $\mathrm{I}(0)$ we did not consider to test for non-stationarity of the series in change.

Since the our theoretical model is cast in terms of aggregate growth rate we justifiably constructed the macroeconometric model with focus on the rate of growth, to be more specific per capital rate of growth to take care of population growth factor. In view of the stationarity of the variables at changes there is no problem in fitting a vector autoregressive model with the five variables mentioned above, viz. per capita growth rate and the rest four in changes. The specified macroeconometric model is:

$$
A y_{t}+a_{0}+A_{1} y_{t-1}+\ldots \ldots+A_{p} y_{t-p}+\beta x_{t}=B e_{t}
$$

where $y_{t}=[\text { Growth_PC } \Delta \text { Edu_ratio } \Delta \text { Health_Ratio } \Delta \text { Infra_Ratio } \Delta \text { Working_pop }]^{\prime}, A=$ matrix of contemporaneous coefficients of the endogenous variables, $a_{0}=$ vector of constants for each equation, $A_{i}=$ coefficient matrix of the lagged endogenous variables, $\beta=$ vector of coefficients for the single exogenous variable of the model, $x_{t}=$ exogenous variable, $B=$ coefficient matrix of the structural shocks, $e_{t}=$ vector of structural shocks. All of the $A_{j}$ 's are $5 \times 5, a_{0}$ and $\beta$ are $5 \times 1, B$ is $5 \times 5$.

The corresponding reduced form Vector Autoregressive (VAR) Model is given by: $y_{t}=\Phi(L)^{-1} B e_{t}=\Pi u_{t}$

where $\Phi(L)=a_{0}+A_{1} y_{t-1}+\ldots \ldots+A_{p} y_{t-p}+\beta x_{t}, \Pi=\Phi(L)^{-1} B$ 
We have normalized on the endogenous variables such that $A$ is an identity matrix. The reduced form VAR, as given by (16) is estimated with a lag of structure of 3 . We chose the lag structure to be 3 by SBI, AIC and Lutkepohl lag order selection statistics. However, for some of the endogenous variables all lagged variables are not significant. The reduced form is estimated with upto 3 lags for the endogenous variables and time as an exogenous variable. ${ }^{3}$ The stability of the VAR model is ensured by the condition that all the eigenvalues of the underlying reduced form coefficient matrix are less than unity. This condition is satisfied which is evident from the Table 3.4 and Fig. 3.1 below. We also tested for Lagrange multiplier test for autocorrelation.

Table 3.4: Eigenvalue stability condition

\begin{tabular}{|c|c|c|c|}
\hline \multicolumn{3}{|c|}{ Eigenvalue } & Modulus \\
\hline & & & \\
\hline & & & \\
\hline . 7960834 & - & . 526143i & .954241 \\
\hline . 8581699 & + & . 2523118i & .894492 \\
\hline .8581699 & - & . 2523118i & .894492 \\
\hline .1020411 & + & . 8162921i & .822645 \\
\hline 1020411 & - & . 8162921i & .822645 \\
\hline - . 7123976 & & & .712398 \\
\hline .278433 & + & .6079097i & .66864 \\
\hline .278433 & - & . $6079097 i$ & .66864 \\
\hline - . 3076073 & + & . 4156409i & .517088 \\
\hline-.3076073 & - & .4156409i & .517088 \\
\hline-.4257593 & + & .199843i & .470328 \\
\hline-.4257593 & - & .199843i & .470328 \\
\hline - . 2530931 & & & .253093 \\
\hline . 2253071 & & & . 225307 \\
\hline
\end{tabular}

\footnotetext{
${ }^{3}$ Without a Time trend the estimated reduced for VAR becomes unstable.
} 


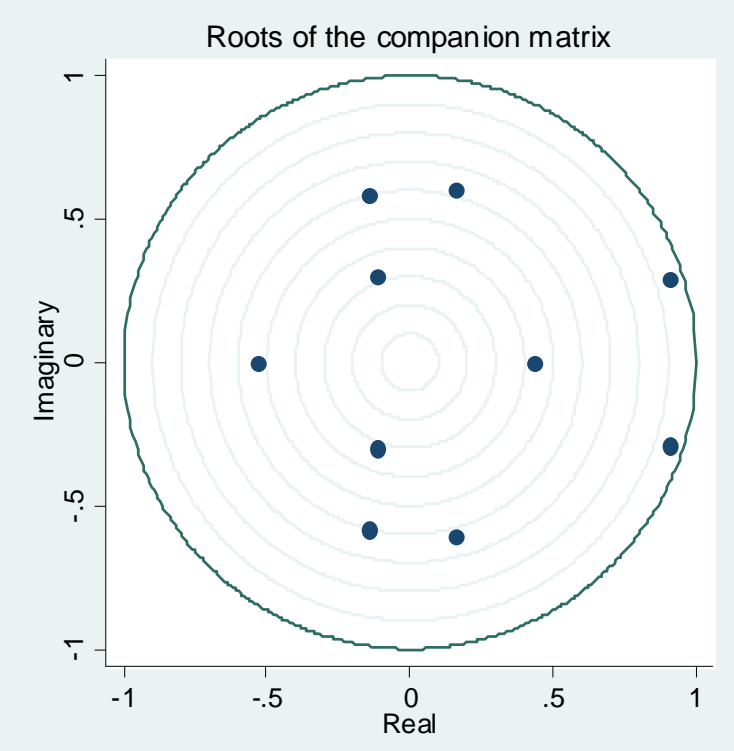

Fig. 3.1: Eigenvalues of the underlying VAR

Finally, we report Granger causality test in Table 3.5. The test procedure is Wald test of the null hypothesis that the lagged coefficients of each of the endogenous variables is zero (first four sub-panels) and that all the lagged coefficients of all the endogenous variables are (last row of each sub panel). As Table 3.5 shows that the null of no Granger causality of per capita growth, change in the rate of educational expenditure and change in the rate of infrastructure expenditure by all the other endogenous variables separately or together cannot be rejected at 5\% level. However, the null hypothesis of no Granger causality of change in rate of health expenditure by the change in the per capita growth rate and rate of health expenditure cannot be rejected, the null is rejected by the change in the rate of infrastructure expenditure (at 5\%) and by the change in the rate of working age population (1\%) and also for the case with all other (lagged) endogenous variables. Finally, the null of no Granger causality of rate of working age population is rejected at $1 \%$ level for all other (lagged) endogenous variables taken together and separately for each of the endogenous variables except for per capita growth rate. 
Table 3.5: Granger Causality Test

\begin{tabular}{|c|c|c|c|c|c|}
\hline Equation & Excluded | & $\mathrm{F}$ & $d f$ & $d f \_r$ & Prob > F \\
\hline Growth_PC & $\Delta$ Edu_Ratio | & .88333 & 3 & 100 & 0.4525 \\
\hline Growth_PC & $\Delta$ Health_Ratiol & .06549 & 3 & 100 & $\odot .9780$ \\
\hline Growth_PC & $\Delta$ Infra_Ratiol & .4478 & 3 & 100 & $\odot .7194$ \\
\hline Growth_PC & $\Delta$ working_pop | & .20165 & 3 & 100 & $\odot .8950$ \\
\hline Growth_PC & ALL I & .43953 & 12 & 100 & 0.9435 \\
\hline$\Delta$ Edu_Ratio & Growth_PC | & 1.4541 & 3 & 100 & $\odot .2317$ \\
\hline$\Delta$ Edu_Ratio & $\Delta$ Health_Ratio| & 1.2834 & 3 & 100 & $\odot .2843$ \\
\hline$\Delta$ Edu_Ratio & $\Delta$ Infra_Ratio | & .51425 & 3 & 100 & 0.6734 \\
\hline$\Delta$ Edu_Ratio & $\Delta$ working_pop | & 2.6024 & 3 & 100 & $\odot .0562$ \\
\hline$\Delta$ Edu_Ratio & ALL I & 1.8134 & 12 & 100 & $\odot .0558$ \\
\hline$\Delta$ Health_Ratio & Growth_PC| & .05935 & 3 & 100 & $\odot .9809$ \\
\hline$\Delta$ Health_Ratio & $\Delta$ Edu_Ratiol & 1.8015 & 3 & 100 & 0.1518 \\
\hline$\Delta$ Health_Ratio & $\Delta$ Infra_Ratiol & 3.9545 & 3 & 100 & 0.0104 \\
\hline$\Delta$ Health_Ratio & $\Delta$ working_pop | & 4.623 & 3 & 100 & 0.0045 \\
\hline$\Delta$ Health_Ratio & ALL I & 2.4155 & 12 & 100 & $\odot .0 \odot 86$ \\
\hline$\Delta$ Infra_Ratio & Growth_PC | & .18742 & 3 & 100 & $\odot .9047$ \\
\hline$\Delta$ Infra_Ratio & $\Delta$ Edu_Ratio | & .4484 & 3 & 100 & $\odot .7190$ \\
\hline$\Delta$ Infra_Ratio & $\Delta$ Health_Ratiol & .60491 & 3 & 100 & 0.6133 \\
\hline$\Delta$ Infra_Ratio & $\Delta$ working_pop | & 1.1447 & 3 & 100 & $\odot .3349$ \\
\hline$\Delta$ Infra_Ratio & ALL I & .44747 & 12 & 100 & 0.9397 \\
\hline$\Delta$ working_pop & Growth_PC | & 1.9422 & 3 & 100 & $\odot .1276$ \\
\hline$\Delta$ working_pop & $\Delta$ Edu_Ratio | & 6.2793 & 3 & 100 & $\odot .0 \odot \odot 6$ \\
\hline$\Delta$ working_pop & $\Delta$ Health_Ratiol & 7.0788 & 3 & 100 & $\odot .0 \odot \odot 2$ \\
\hline$\Delta$ working_pop & $\Delta$ Infra_Ratio | & 3.841 & 3 & 100 & 0.0119 \\
\hline$\Delta$ working_pop & ALL | & 4.7761 & 12 & 100 & $\odot .0000$ \\
\hline
\end{tabular}

To summarize the above results none of the fiscal variables and the rate of working population Granger cause rate of per capita growth rate. However, all the fiscal policy variables Granger cause rate of working age population, but the per capita growth rate does not Granger cause rate of working age population.

All the above results pertain to the reduced form VAR which are though very important, cannot directly shed light on the economic relations that are ultimately interested in. The estimation of the theoretical model or testing of some specific hypothesis is conducted on the basis of a structural vector autoregressive (SVAR) model derived from the 
reduced form VAR (see Enders, 2009; Hamilton 1994; Kehoe, 2006, Lutkepohl and Kratzig, 2004; Sims, 1980; Stock and Watson, 2001 for alternative approaches to this issue). The underlying SVAR model from the VAR estimated from (16) can be recovered by putting some conditions - identification conditions on the coefficients of the SVAR model. There are two types of SVAR depending on the nature of restrictions on the coefficients of the structural model - short run VAR and long run SVAR. Since our focus is growth and demography which are by definition long run in nature we will work with the long run SVAR model. Equation (16) can be written as

$$
y_{t}=\Phi(L)^{-1} B e_{t}=C e_{t}
$$

where $C=\Phi(L)^{-1} B$ is the matrix of long run responses to the orthogonalized shocks. This is there are 25 structural parameters in the SVAR model which we have to estimate from the reduced form VAR. One has to put at least $2 K^{2}-K(K+1) / 2=10$ restrictions for the satisfaction of the order condition of identification. Typically the restrictions in the long run model are exclusion restrictions. The restriction that $C_{i j}=0$ means the long run response of the $j^{\text {th. }}$ structural shock has no effect on the $i^{\text {th. }}$ endogenous variable. We put zero restriction on the long run response of the fiscal variables. There is only one zero restriction on the coefficient of the rate of working age population for the shock to growth rate. This is found to be appealing from the Granger causality test (though it is not a test of exogeneity). It is also a compulsion for the satisfaction of the identification condition. However, we also re-estimated the model with no restriction on the rate of working age population but a zero restriction on the growth rate equation. There is no change in the results as the relevant coefficient is found 
Table 3.6: The estimated coefficient matrix of the exactly identified SVAR

\begin{tabular}{|c|c|c|c|c|}
\hline $\begin{array}{c}0.0139886 \\
(8.72)\end{array}$ & $\begin{array}{c}0.005351 \\
(2.26)\end{array}$ & $\begin{array}{c}-0.0008156 \\
(-0.33)\end{array}$ & $\begin{array}{c}0.0069474 \\
(2.69)\end{array}$ & $\begin{array}{c}-0.0019433 \\
(-0.85)\end{array}$ \\
\hline 0 & $\begin{array}{c}0.0004348 \\
(8.72)\end{array}$ & $\begin{array}{c}-0.00000184 \\
(-0.03)\end{array}$ & $\begin{array}{c}0.0002107 \\
(2.83)\end{array}$ & 0 \\
\hline 0 & 0 & $\begin{array}{c}0.0004411 \\
(8.72)\end{array}$ & $\begin{array}{c}0.0001966 \\
(2.62)\end{array}$ & 0 \\
\hline 0 & 0 & 0 & $\begin{array}{c}0.0059892 \\
(8.72)\end{array}$ & 0 \\
\hline 0 & $\begin{array}{c}-0.0092929 \\
(-1.88)\end{array}$ & $\begin{array}{c}0.0224791 \\
(3.96)\end{array}$ & $\begin{array}{c}-0.0120045 \\
(-1.88)\end{array}$ & $\begin{array}{c}0.0297428 \\
(8.72)\end{array}$ \\
\hline
\end{tabular}

Note: (1) Obsns. from 1970-2010.

(2) The figures in the parentheses are t-statistics.

to be non-significant. Since some of the coefficients are reported to be non-significant we reestimated the SVAR model with zero restriction for those coefficients. The reestimated long run coefficient matrix coefficient matrix is given below. The Likelihood Ratio test of identifying restrictions: $\operatorname{chi} 2(3)=0.8466$ (Prob $>$ chi2 $=0.838$ ) which implies that the overidentifying restrictions cannot be rejected.

Table 3.7: Estimated coefficients of the over identified SVAR

\begin{tabular}{|c|c|c|c|c|}
\hline $\begin{array}{c}0.0171007 \\
(8.72)\end{array}$ & $\begin{array}{c}0.0064732 \\
(2.25)\end{array}$ & 0 & $\begin{array}{c}0.008399 \\
(2.69)\end{array}$ & 0 \\
\hline 0 & $\begin{array}{c}0.0005257 \\
(8.72)\end{array}$ & 0 & $\begin{array}{c}0.0002547 \\
(2.83)\end{array}$ & 0 \\
\hline 0 & 0 & $0.0005333(8.72)$ & $\begin{array}{c}0.0002377 \\
(2.62)\end{array}$ & 0 \\
\hline 0 & 0 & 0 & $\begin{array}{c}0.0072406 \\
(8.72)\end{array}$ & 0 \\
\hline 0 & $\begin{array}{c}-0.0112346 \\
(-1.88)\end{array}$ & $\begin{array}{c}0.0271283 \\
(4.1)\end{array}$ & $\begin{array}{c}-0.0145128 \\
(-1.88)\end{array}$ & $\begin{array}{c}0.0359573 \\
(8.72)\end{array}$ \\
\hline
\end{tabular}

Note: (1) Obsns. from 1970-2010.

(2) The figures in the parentheses are t-statistics.

In matrix notation we can write our final SVAR model as in below.

$\left[\begin{array}{ccccc}0.0171007 & 0.0064732 & 0 & 0.008399 & 0 \\ 0 & 0.0005257 & 0 & 0.0002547 & 0 \\ 0 & 0 & 0.0005333 & 0.0002377 & 0 \\ 0 & 0 & 0 & 0.0072406 & 0 \\ 0 & -0.0112346 & 0.0271283 & -0.0145128 & 0.0359573\end{array}\right]\left[\begin{array}{l}\text { Growth_PC } \\ \Delta \text { Edu_ratio } \\ \Delta \text { Health_Ratio } \\ \Delta \text { Infra_Ratio } \\ \Delta \text { Working_pop }\end{array}\right]=\left[\begin{array}{l}\mathrm{e}_{1} \\ \mathrm{e}_{2} \\ \mathrm{e}_{3} \\ \mathrm{e}_{4} \\ \mathrm{e}_{5}\end{array}\right]$


It is evident from the final SVAR model that per capita growth increases due to structural shocks in rates of education and infrastructure-related expenditures. A shock to the rate of education expenditure affects changes in the rate of health expenditure. Note that, changes in the rate of infrastructure expenditure are purely exogenous. Further, changes in the rate of working age population are manifested by shocks originating from changes in all the fiscal variables. In fact, the effect of the rate of education expenditure and infrastructure expenditure are negative while the change in the rate of health expenditure is positive. Rate of working age population neither affects nor is affected by the rate of per capita growth.

Next, we plot the impulse response functions and variance decomposition functions for the per capita growth rate and rate of working age population in Figs. 3.2 through 3.7 with impulses arising from the three fiscal variables. In general, it is readily observed that the impulse variables have varying impacts on the response variables. The impact of a shock from education expenditure or from health expenditure on to the working age population, as well as per capita growth rate, are similar in nature displaying short-run effects. After a few years, the path in both the cases comes back to its original trajectory. However, the impacts of the shocks move in opposite directions. While education expenditure has a dampening effect on the working age population, the health expenditure raises it. The rate of growth initially decreases following a shock to the health expenditure, while it increases from a shock to education expenditure though eventually, both of them return to their original trajectories. As for the shock to infrastructure expenditure, the effects are different for the two response variables. For per capita growth rate, the impact is short term, while for the working age population it is permanent. 


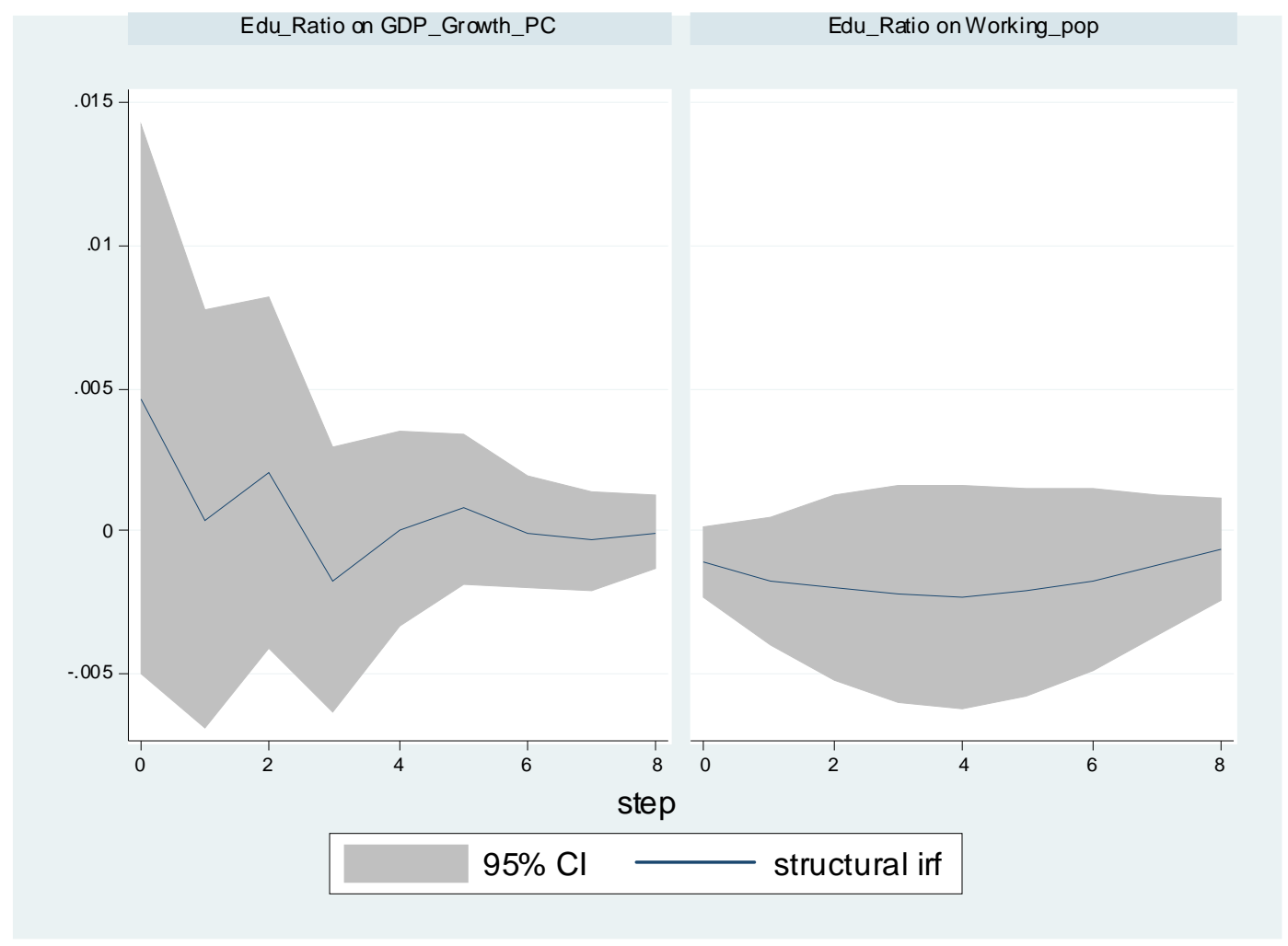

Fig. 3.2: Impulse Response Function - Impulse by Education expenditure

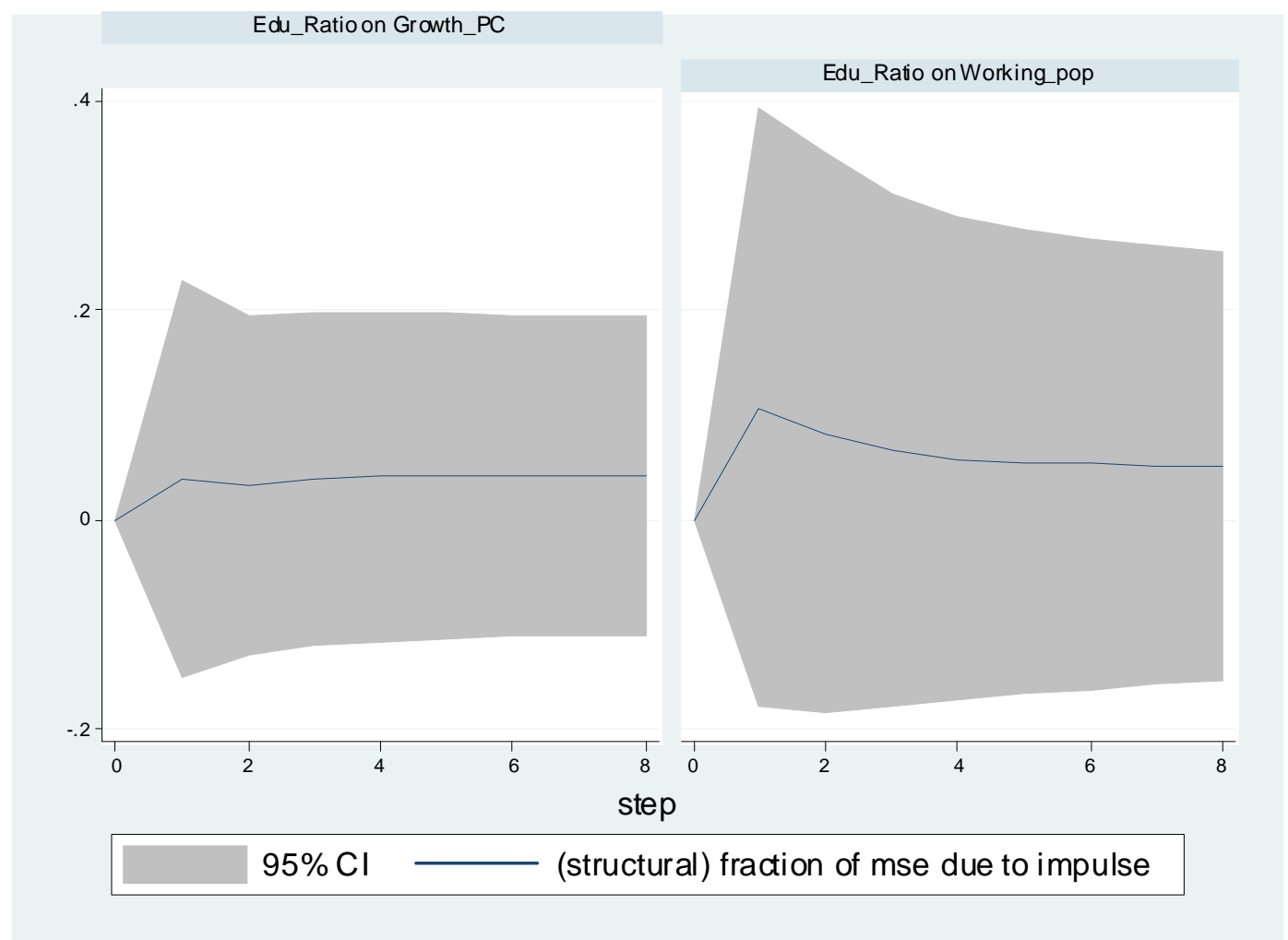

Fig. 3.3: Variance Decomposition - Impulse by Education expenditure 


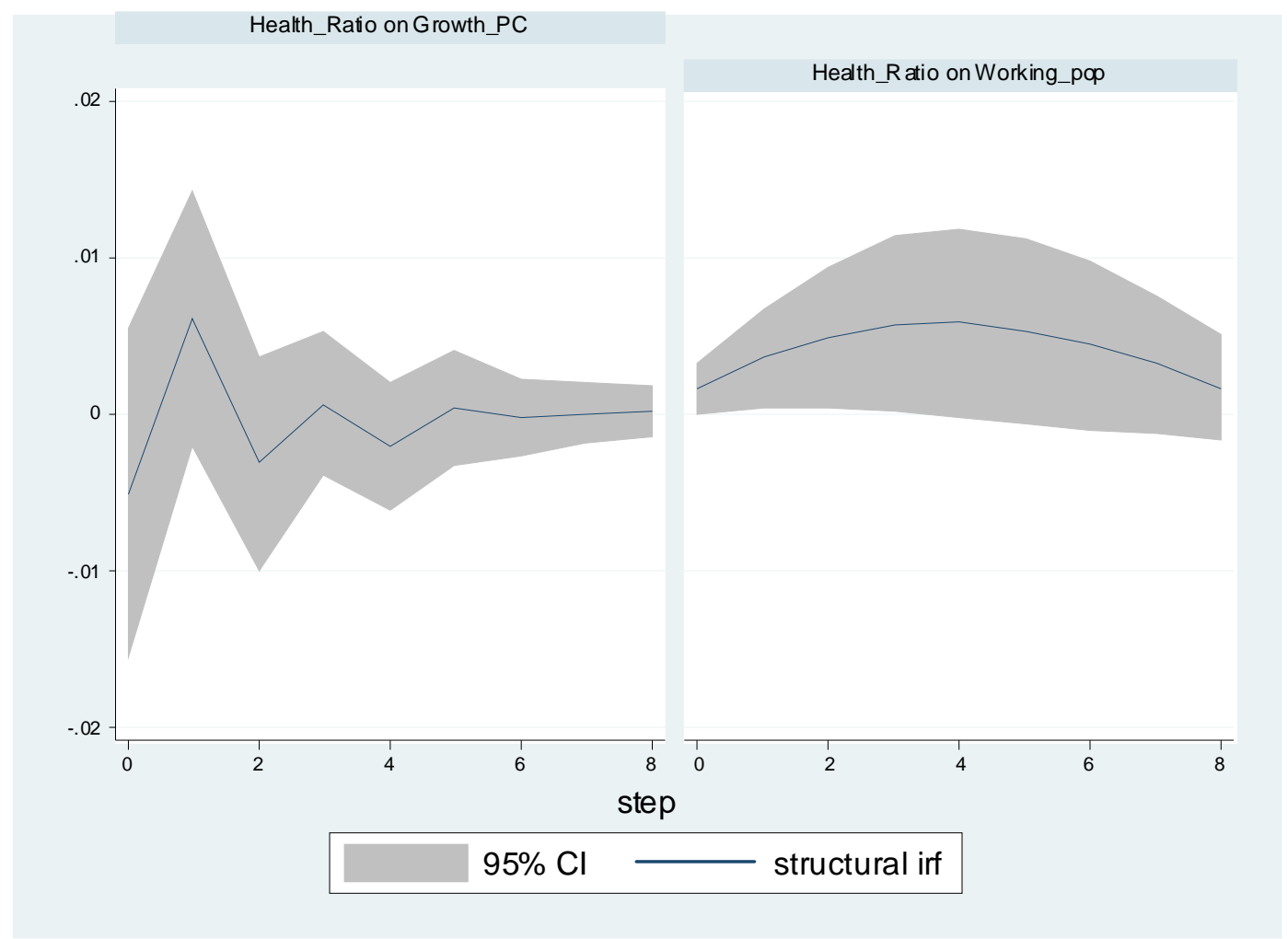

Fig. 3.4: Impulse Response Function - Impulse by Health expenditure

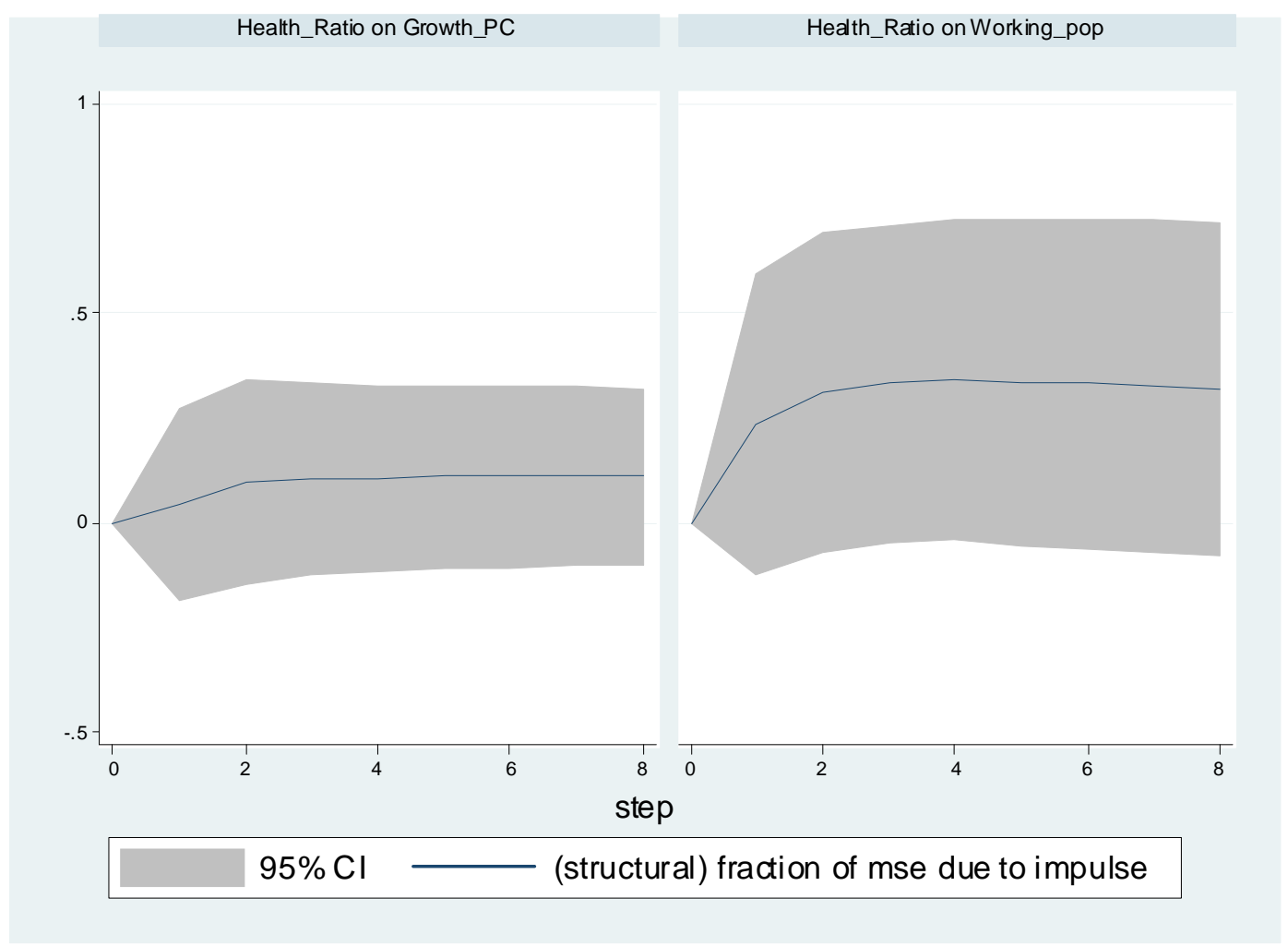

Fig. 3.5: Variance Decomposition - Impulse by Health expenditure 


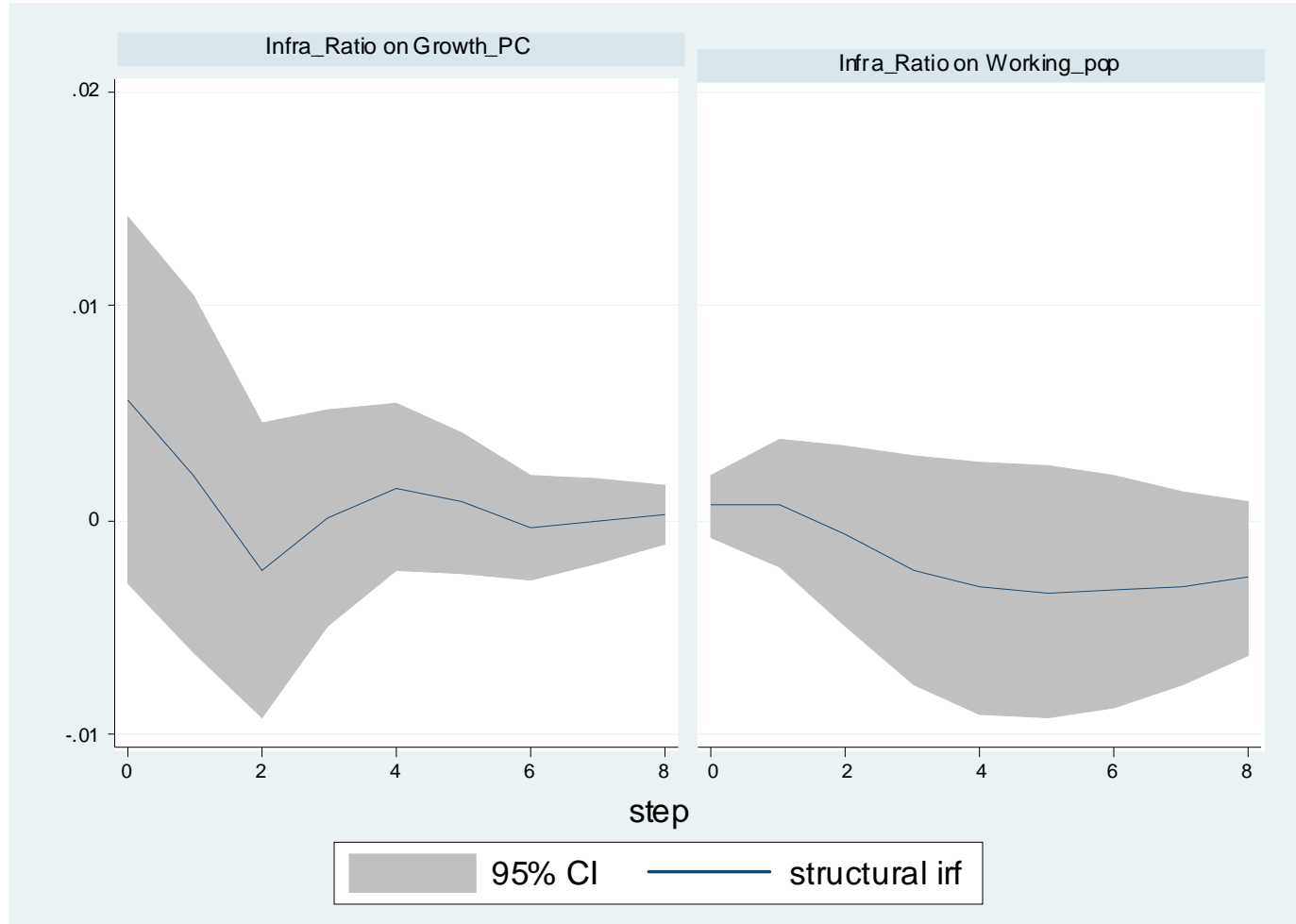

Fig. 3.6: Impulse Response Function - Impulse by Infrastructure expenditure

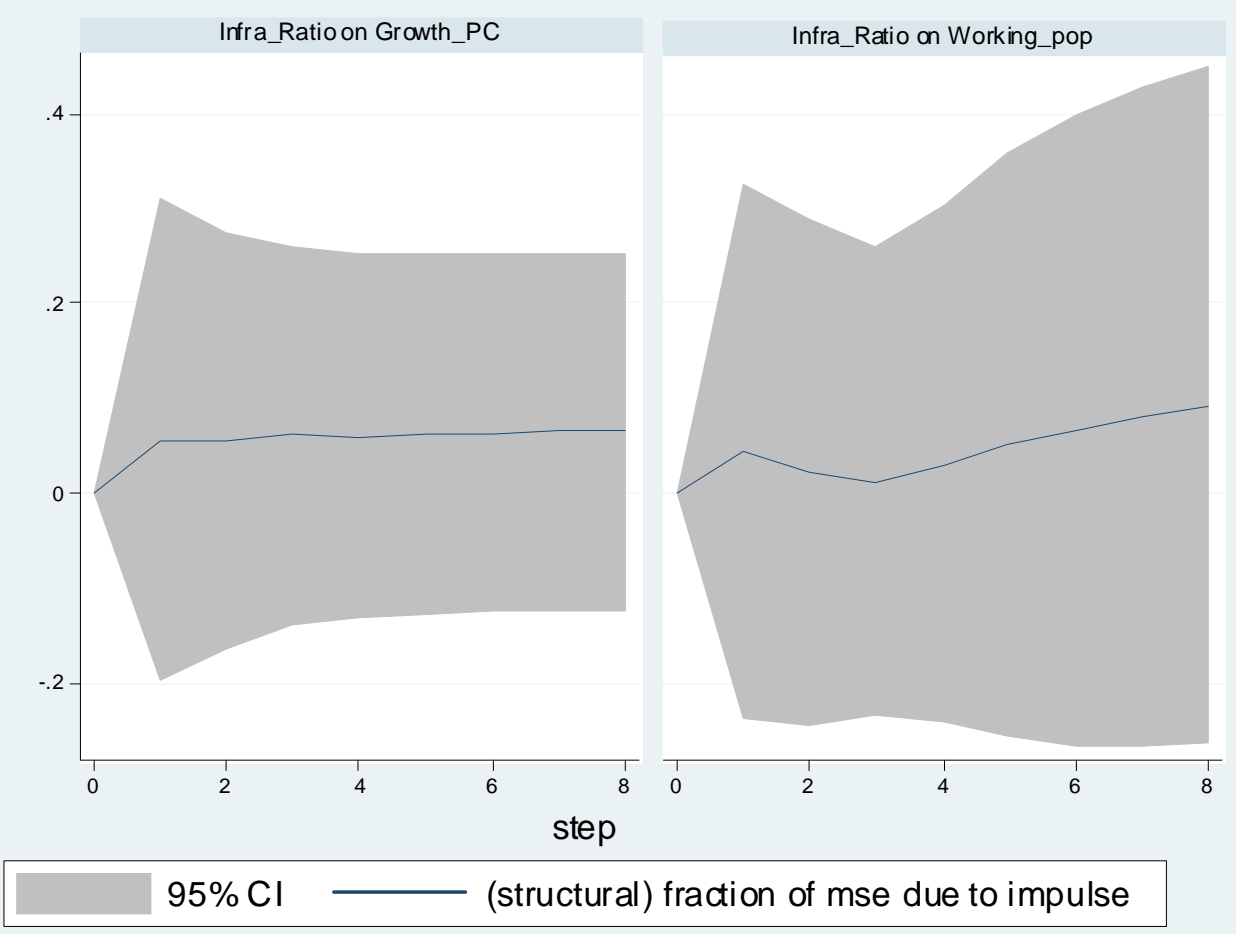

Fig. 3.7: Variance Decomposition - Impulse by Infrastructure expenditure 
These observations are quite consistent with the coefficients of the constrained long run SVAR model defined by equation (18).

\section{Concluding Remarks}

The paper developed a theoretical model explaining the role of fiscal parameters on the demographic factors and its effects on the rate of growth in an economy. We considered two important fiscal policy variables - the share of expenditure on education and health, which are expected to influence the productivity of the working age population in the long run. A higher productivity of the working age population is expected to raise the growth rate, which in turn is significantly determined by the strength of human capital as direct outcomes of public and private investments. For a developing country like India, the role of public intervention continues to be unambiguously high.

The observed effects operate in two different ways - one, the expenditure on education directly affects technical knowledge and two, the health-related expenditure affects sheer productive capacity even for the unskilled labor. In many cases, the budgetary allotment in these social sectors are easier said than done, typically because there are competing claimants from infrastructure and other areas of national importance. We did not include infrastructure in our theoretical model as it is generally undisputed to have a crowding-in effect from private investment, with direct implications for growth. However, we did include infrastructure expenditure in our econometric model to observe if the trade-off arising from atypical public budgetary constraints reflects adversely on the overall growth rate.

Based on the arguments of the theoretical section we formulated an econometric model where we allowed three fiscal policy variables to interact. The results of the empirical 
section - in terms of the estimated SVAR model and the impulse response functions - show important roles played by the social sector expenditure affecting the rate of working age population with implications for labor force participation. The growth rate is positively affected by the expenditure on education and infrastructure, but not by the expenditure on health. However, expenditures on education and infrastructure negatively affect the working age population, but health expenditure affects it favorably. The intuition should be straightforward. The expenditures on education and infrastructure operate through different channels. A rise in the public expenditure in education creates better opportunities for a larger share of the population to enroll for school and colleges leading to lower work force participation. Conversely, the present spurt of public investment on infrastructure, at least as far as India is concerned, has engendered the scope for the service sector much more than the traditional large manufacturing units. The new industries, if any are also less labor intensive than their predecessors. This implies that despite infrastructure (telecommunication, transport, logistic supports, etc) growth, the workforce participation did not rise significantly. Needless to mention, a number of studies already exist which analyze the sector-specific behavior and should be able to substantiate the empirical results we generate from a different perspective.

Finally, it is possible to extend the present paper by incorporating private expenditure on education, health and capital formation and investigate in greater detail how they interact with the corresponding public expenditures and the implications for the working age population, labor force participation and growth rate. 


\section{References}

Albrieu, Ramiro and Jose Maria Fanelli (2012), On the Macroeconomic and Financial Implications of the Demographic Transition, Paper presented in IX Meeting of the Working Group on Macroeconomic Aspects of Intergenerational Transfers, Faculty of Economics, University of Barcelona, June 3-8, 2013.

Barro, R. (1999) Human Capital and Growth in Cross Country Regressions. Swedish Economic Policy Review, 6, 237-277.

Basu, Kaushik (1997), Analytical Development Economics. The Less Developed Economy Revisited, Cambridge, Mass: MIT Press.

Das, Pranab Kumar and Saibal Kar (2015), A Study of Demographic and Financial Development in India. In Ramiro Albrieu and Jose Maria-Fanelli eds. Asymmetric Demography and the Global Economy: Growth Opportunities and Macroeconomic Challenges in an Ageing World, Palgrave Macmillan, New York.

Dyson, Tim (2008), India's Demographic Transition and its Consequences for Development, Golden Jubilee Lecture Series, Institute of Economic Growth, New Delhi.

Government of India (1991), National Sample Survey Organisation, All India Debt and Investment Survey, Mumbai.

Government of India (2002), National Sample Survey Organisation, All India Debt and Investment Survey, Mumbai.

Government of India (2007), National Sample Survey Organisation, Unorganised Manufacturing Sector in India: Input, Output and Value Added 2005-06, 62nd Round, Report No. 526(62/2.2/3).

Government of India (2007), National Sample Survey Organisation, Operational Characteristics of Unorganised Manufacturing Enterprises in India 2005-06, 62nd Round, Report No. 524(62/2.2/1).

Government of India (2008), A Report on the Success and Failure of SHG's in India Impediments and Paradigm of Success, Planning Commission of India, New Delhi.

Grossman, M., 1972. "On the Concept of Health Capital and the Demand for Health". Journal of Political Economy, 80: 223-255.

Gutierrez, C, P. Paci and B. Park (2010), Understanding the Impact of Economic Shocks on Labor Market Outcomes in Developing Countries An application to Indonesia and Mexico, World Bank Policy Research Working Paper 5283. Washington DC.

Gyimah-Brempong K, Wilson M. 2004. Health, human capital, and economic growth in sub-Saharan African and OECD countries. Quarterly Review of Economics and Finance, 44, 296-320. 
Hokayem, C and J. Ziliak (2014), Health, Human Capital, and Life Cycle Labor Supply The American Economic Review, 104, 5, 127-131

Itskhoki, O and B. Moll (2014), Optimal Development Policies with Financial Frictions, NBER Working Paper No. 19994, Cambridge: MA.

James, K. S. and S. V. Subramanian (2003), Towards a Demographic Transition”, Economic and Political Weekly, 38, 12-13.

Hamilton, James D. (1994), Time Series Analysis, Princeton University Press, Princeton New Jersy.

Kehoe, P. J. (2006), How to advance theory with structural VARS: Use the Sims-CogleyNason Approach, Working Paper 12575, NBER, Cambridge: MA.

Knowles, S. and P. Owen, (1997), Education and Health in an Effective-Labour Empirical Growth Model, Economic Record, 73, 223, 314-28.

Ladusingh, L. and M. R. Narayana (2011), Demographic Dividends for India: Evidence and Implications Based on National Transfer Accounts, ADB Economics Working Paper Series No. 292, Manila: Philippines.

Lee, J. and Strazicich, M. (2001), Testing the null hypothesis of stationarity in the presence of structural breaks. Applied Economic Letters, 8, 377-382.

Lutkepohl, H. and M. Kratzig, (2004), Applied Time Series Econometrics, Cambridhe University Press, Cambridge, Massachusetts.

Nixon, J. and P. Ulmann, (2006), The Relationship Between Health Care Expenditure and Health Outcomes, European Journal of Health Economics, 7, 7-18.

Reserve Bank of India (2012), Database of Indian Economy, Mumbai http://dbie.rbi.org.in/DBIE/dbie.rbi?site=home

Reserve Bank of India (2006), Annual Policy Statement for the Year 2006-07, Mumbai

Romer, D (1996), Advanced Macroeconomics, McGraw-Hill, NY.

Sims, C. A. (1980), Macroeconomics and reality, Econometrica, 48, 1-48.

Stock, J. H. and M. W. Watson (2001), Vector Autoregression, Journal of Economic Perspectives, 15, 4, 101-115.

Visaria, L (2009), Demographic Transition in India, in: Yogesh Atal Ed. Sociology and Social Anthropology in India, ICSSR survey of Advances in Research, Pearson, New Delhi.

World Bank (2012), World Development Indicators, Washington DC. World Bank. 
Zivot, E. and Andrews, D.W.K. (1992), Further evidence on the great crash, the oil price shock and the unit root hypothesis. Journal of Business and Economic Statistics, 10, 251-270. 